This Health Hazard Evaluation ( $\mathrm{HHE}$ ) report and any recommendations made herein are for the specific facility evaluated and may not be universally applicable. Any recommendations made are not to be considered as final statements of NIOSH policy or of any agency or individual involved. Additional HHE reports are available at http://www.cdc.gov/niosh/hhe/reports

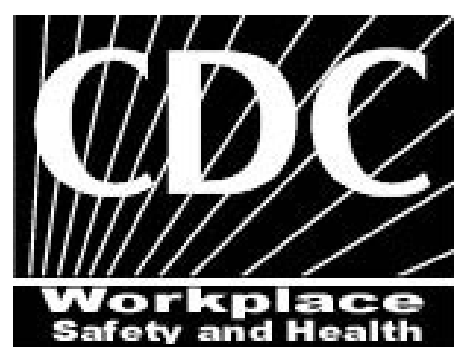

NIOSH HEALTH HAZARD EVALUATION REPORT:

HETA \#2000-0066-2892

United States Air Force

Davis-Monthan Air Force Base

Tucson, Arizona

\title{
September 2002
}

DEPARTMENT OF HEALTH AND HUMAN SERVICES

Centers for Disease Control and Prevention

National Institute for Occupational Safety and Health

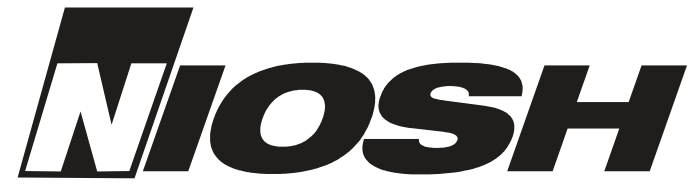




\title{
PREFACE
}

The Hazard Evaluations and Technical Assistance Branch (HETAB) of the National Institute for Occupational Safety and Health (NIOSH) conducts field investigations of possible health hazards in the workplace. These investigations are conducted under the authority of Section 20(a)(6) of the Occupational Safety and Health (OSHA) Act of 1970, 29 U.S.C. 669(a)(6) which authorizes the Secretary of Health and Human Services, following a written request from any employer or authorized representative of employees, to determine whether any substance normally found in the place of employment has potentially toxic effects in such concentrations as used or found.

HETAB also provides, upon request, technical and consultative assistance to Federal, State, and local agencies; labor; industry; and other groups or individuals to control occupational health hazards and to prevent related trauma and disease. Mention of company names or products does not constitute endorsement by NIOSH.

\section{ACKNOWLEDGMENTS AND AVAILABILITY OF REPORT}

This report was prepared by Ann Krake, Brad King, and Joel McCullough of HETAB, Division of Surveillance, Hazard Evaluations and Field Studies. Field assistance was provided by Sergeant Douglas Fritts and Sergeant Joyce Foster, United States Air Force (USAF). Pre- and post-activity body weight data were provided by Dr. Amit Bhattacharya, Edward Auyang, Jessica Gordan, Dr. Laurel Kincl, Ming Lun Lu, and Terry Mitchell, University of Cincinnati, Department of Environmental Health, College of Medicine, Cincinnati, Ohio. Dr. Paul Jensen, Stephen Martin, Earnest Moyer, and Stephen Berardinelli, NIOSH, Division of Respiratory Disease Studies, Morgantown, West Virginia, provided field assistance and field notes essential to this report. Dr. Thomas E. Bernard, University of South Florida, College of Public Health, Tampa, Florida, provided essential guidance on the report's content for which the authors are very grateful. Desktop publishing was performed by David Butler. Review and preparation for printing were performed by Penny Arthur.

The authors would like to thank the USAF for the loan of the core body temperature monitors and Ms. Lindy McCollum-Brounley, formerly of HTI Technologies, Palmetto, Florida, for her support and guidance in the use of the $\mathrm{CorTemp}^{\mathrm{TM}}$ monitoring system, as well as HTI's generous equipment loans. The authors are especially thankful for the help provided by many of the JP-8 jet fuel study investigators including principal Major Leslie B. Smith (Ret.), and coinvestigators Major Donald Christianson, and Lieutenant Colonel Roger Gibson, USAF. Technical support and guidance were provided by Mr. Allen Meyers, Sergeant David Villareal, Major Brian Blazicko, Sergeant Sally Perez, Sergeant Michael Lasenby, and Major Shawn Moore, USAF.

Copies of this report have been sent to employee and management representatives at Davis-Monthan AFB. This report is not copyrighted and may be freely reproduced. Single copies of this report will be available for three years from the date of this report. To expedite your request, include a self-addressed mailing label with your request to:

\author{
NIOSH Publications Office \\ 4676 Columbia Parkway \\ Cincinnati, Ohio 45226 \\ 800-356-4674
}

After this time, copies may be purchased from the National Technical Information Service (NTIS) at 5825 Port Royal Road, Springfield, Virginia 22161. Information regarding the NTIS stock number may be obtained from the NIOSH Publications Office at the Cincinnati address.

For the purpose of informing affected employees, copies of this report shall be posted by the employer in a prominent place accessible to the employees for a period of 30 calendar days. 


\section{Evaluation of Heat Stress in Fuel Systems Maintenance Personnel at Davis-Monthan Air Force Base}

During the week of April 10-14, 2000, NIOSH representatives conducted a health hazard evaluation at Davis-Monthan (D-M) Air Force Base (AFB), Tucson, Arizona. We looked into management concerns about personnel exposures to high temperatures while conducting fuel systems maintenance (FSM) activities.

\section{What NIOSH Did}

- We measured the temperatures outside and inside the hangar. We also measured how much work (work load) the employees did.

- About half of the employees were weighed before and after their work and were tested for dehydration (not enough water in their bodies).

- We measured the heart rates and internal body temperatures of the employees while they did their work.

- We talked to the employees about their jobs and asked them to tell us their health concerns.

\section{What NIOSH Found}

- The FSM employees were not exposed to excess heat stress and none got sick from the heat.

- Five of twenty-five FSM employees had heart rates and/or body temperatures that were high enough during parts of their shift that they were more likely to get sick from the heat than those who didn't have high heart rates or body temperatures.

- Nine of twelve FSM employees became at least mildly dehydrated during their shift, and two lost over $1.5 \%$ of their body weight. Employees who lose weight during their shift are more likely to get sick from the heat.

- None of these employees knew they had heat strain and/or dehydration and did not know they were in danger of getting sick from the heat.

- D-M AFB has a formal heat stress management program, but the program does not teach employees how to monitor themselves for heat strain.

\section{What D-M Managers Can Do}

- Add a heat strain (physiological) monitoring program to the base instruction for heat stress that will:

- teach personnel the reasons for and benefits of listening to their bodies when they are heat stressed;

- train personnel in personal monitoring techniques;

- encourage employees to use the buddy system to monitor themselves and others' heat stress and strain signs.

- Conduct heat strain monitoring when air- and vaporimpermeable encapsulating suits are required and/or when dry bulb temperatures exceed $68^{\circ} \mathrm{F}$.

- Take wet bulb globe temperature measurements as close to the work area as possible, and take readings hourly during the hottest part of the shift and hottest months of the year.

\section{What D-M Personnel Can Do}

- Learn to monitor yourself and your co-workers for heat stress and strain, and take breaks when needed before you get sick.

- Some of the first signs of heat strain, lack of good judgement and inability to think critically, usually are not noticed by the person who is getting sick from the heat. Therefore, make sure you are well-hydrated, have eaten enough, and have slept well before you work in the heat.

- Avoid getting sick from drinking too much water. Eat three meals a day, and eat snacks with the water you drink between meals.

- Report any heat-related illnesses and other concerns to your crew leader or commanding officer.

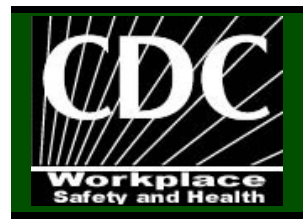

What To Do For More Information:

We encourage you to read the full report. If you would like

a copy, either ask your health and safety representative to

make you a copy or call 1-513-841-4252 and ask for

HETA Report \# 2000-0066-2892

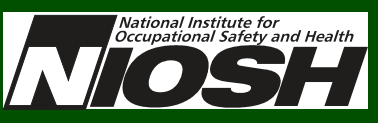




\title{
Health Hazard Evaluation Report 2000-0066-2892 United States Air Force, Davis-Monthan Air Force Base Tucson, Arizona September 2002
}

\author{
Ann M. Krake, MS, REHS \\ Bradley S. King, MPH \\ Joel E. McCullough, MD, MPH
}

\section{SUMMARY}

The National Institute for Occupational Safety and Health (NIOSH) received a health hazard evaluation (HHE) request from the management of the United States Air Force Institute for Environmental, Safety, and Occupational Risk Analysis (AFIERA), Brooks Air Force Base(AFB), San Antonio, Texas. The request indicated that Air Force recruits employed as aircraft fuel systems inspection and repair workers at Davis-Monthan AFB, Tucson, Arizona, were exposed to heat stress, jet fuel, and jet fuel vapors in confined spaces (aircraft fuel tanks). The employees reported experiencing dizziness, lethargy, skin irritation, and a 'jet-fuel taste' during and long after exposure to jet fuel. The requesters asked NIOSH to evaluate the heat stress aspects of the employee complaints and make recommendations to prevent heat illness among the employees. The evaluation was part of an on-going collaborative study of Air Force employees' acute exposure to jet fuel (JP-8), and the other concerns were addressed by this larger study.

Data were collected April 10-14, 2000. Individual and task-specific metabolic rates were estimated, and wet bulb globe temperatures (WBGTs) were measured. Heat strain monitoring included core body temperature (CBT) and heart rate measurements on 25 participants and pre- and post-shift body weight measurements on 12 participants.

The sampling results were compared to the NIOSH recommended action limits and recommended exposure limits (RALs/RELs) and the American Conference of Governmental Industrial Hygienists (ACGIH ${ }^{\circledR}$ ) Threshold Limit Values $\left(\mathrm{TLVs}^{\circledR}\right)$. NIOSH and ACGIH assess heat stress using sliding scale limits based on environmental and metabolic heat loads. In addition, ACGIH provides physiological heat strain limits useful for those wearing impermeable personal protective equipment (PPE) and in situations of excess heat stress. For individuals with normal cardiac performance, ACGIH recommends that sustained (over several minutes) heart rate should remain below 180 beats per minute (bpm) minus age (in years), maximum CBT should remain below $100.4^{\circ} \mathrm{F}$ for unselected, unacclimatized personnel $\left(101.3^{\circ} \mathrm{F}\right.$ for medically selected, acclimatized personnel), recovery heart rate at one minute after a peak work effort should be below $110 \mathrm{bpm}$, and there should be no symptoms of sudden and severe fatigue, nausea, dizziness, or lightheadedness.

The results of the evaluation indicated that all of the participants were acclimatized to their work environment and that none were exposed to heat stress conditions in excess of the screening criteria. However, 5 of 25 participants (20\%) experienced heat strain signs (CBT and/or HR in excess of the ACGIH criteria). In addition, 2 of 12 participants (17\%) had greater than $1.5 \%$ body weight loss over their shifts indicating they were at greater risk of developing a heat-related illness. Seven participants (58\%) developed mild dehydration (any body weight loss of $1.5 \%$ or less) during their job activities. Overall, body weight changes ranged from $-2.3 \%$ to $+0.6 \%$, with a median percent body weight change of $-0.3 \%$.

Because of the work environment, the potential for heat strain increases as temperatures rise during the spring and summer. This factor and the study results justify continuing to include personnel in the Davis-Monthan AFB heat 
stress management program. In addition, participants were not aware of having developed heat strain, indicating a need for a physiological self-monitoring program to be added to the heat stress program.

During our evaluation, health hazards from environmental conditions and overwork did not exist for fuel cell maintenance and other workers. However, hazardous environmental conditions can exist during spring and summer, and $20 \%$ of participants developed heat strain as indicated by the physiological monitoring results (CBT and heart rate levels in excess of occupational criteria). Also, of the 12 participants who were weighed pre- and post-shift, 9 developed at least mild dehydration and 2 were dehydrated. Davis-Monthan AFB has a formal heat stress program and a system for reporting heat-related illnesses. Recommendations are made to implement physiological (heat strain) monitoring, to develop an acclimatization schedule, and to take WBGT measurements in or around immediate work areas at least hourly during the hottest parts of the shift and hottest months of the year.

Keywords: SIC 9711 (National Security). Heat stress, heat strain, heat-related illness, core body temperature, metabolic rates, WBGT, wet-bulb globe temperatures, Air Force aircraft fuel cells, aircraft fuel cell maintenance, fuel systems maintenance, FSM. 


\section{TABLE OF CONTENTS}

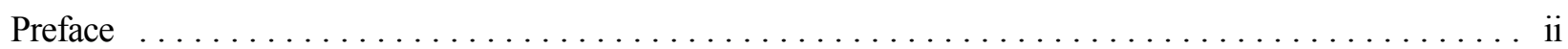

Acknowledgments and Availability of Report $\ldots \ldots \ldots \ldots \ldots \ldots \ldots \ldots \ldots \ldots \ldots \ldots \ldots \ldots \ldots \ldots$

Highlights of the HHE Report $\ldots \ldots \ldots \ldots \ldots \ldots \ldots \ldots \ldots \ldots \ldots \ldots \ldots \ldots \ldots \ldots \ldots \ldots \ldots \ldots \ldots$

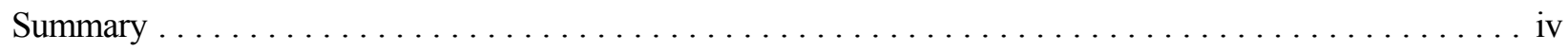

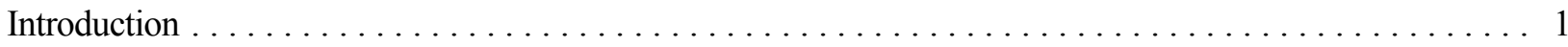

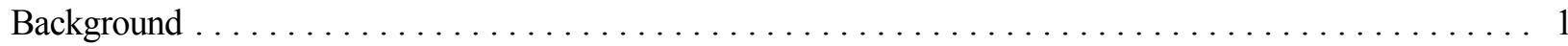

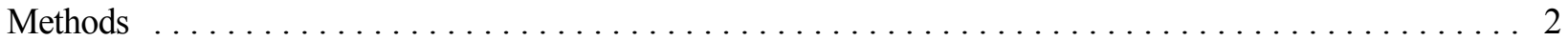

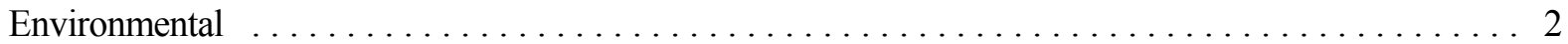

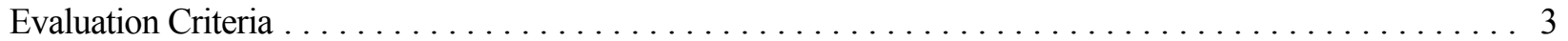

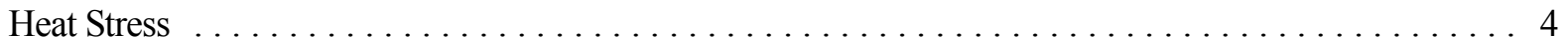

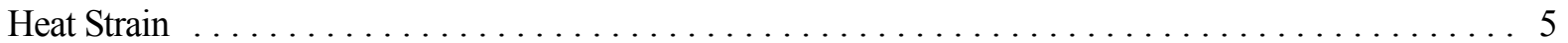

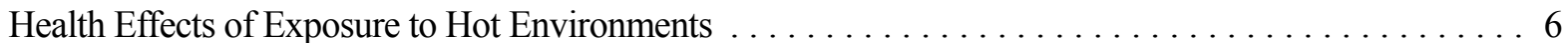

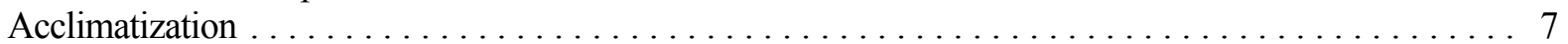

Dehydration and Fluid Replacement $\ldots \ldots \ldots \ldots \ldots \ldots \ldots \ldots \ldots \ldots \ldots \ldots \ldots$

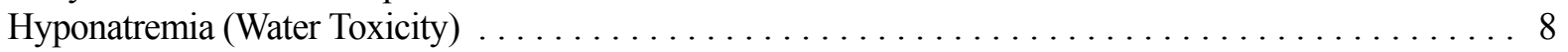

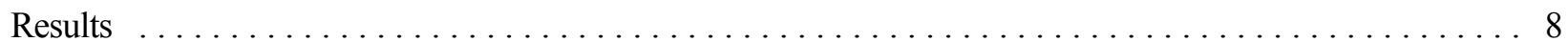

Workload and Task Assessments (Heat Stress) $\ldots \ldots \ldots \ldots \ldots \ldots \ldots \ldots \ldots \ldots \ldots \ldots$

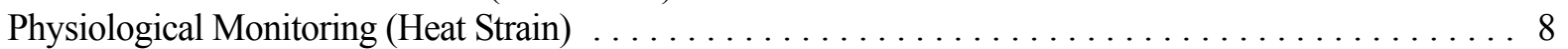

Heat Stress Management at Davis-Monthan AFB $\ldots \ldots \ldots \ldots \ldots \ldots \ldots \ldots \ldots \ldots \ldots \ldots \ldots \ldots \ldots \ldots \ldots$

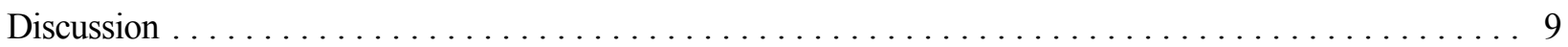

General Observations of the Davis-Monthan Heat Stress Instruction (48-1, 1 July 2000) . . . . . . 10

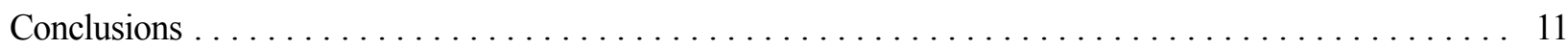

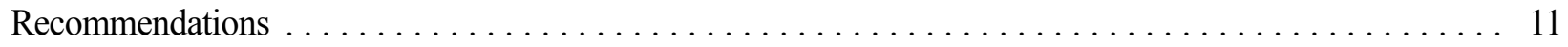

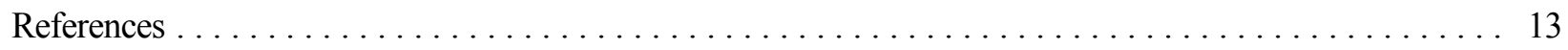




\section{INTRODUCTION}

The National Institute for Occupational Safety and Health (NIOSH) received a health hazard evaluation (HHE) request from the management of the United States Air Force (USAF) Institute for Environmental, Safety, and Occupational Risk Analysis (AFIERA), Brooks Air Force Base (AFB), San Antonio, Texas. The request indicated that Air Force recruits employed as aircraft fuel systems maintenance inspection and repair (FSM) workers, at DavisMonthan (D-M) AFB, Tucson, Arizona, were exposed to heat, jet fuel, and jet fuel vapors in confined spaces (aircraft fuel tanks). The employees reported experiencing dizziness, lethargy, skin irritation, and a 'jet-fuel taste' in their mouths during and long after exposure to jet fuel.

The D-M AFB heat stress evaluation was conducted as part of a collaborative study of Air Force employees' acute exposure to jet fuel(JP-8). The JP8 study was conducted over one year at seven bases located throughout the southern and southwestern U.S. and included 324 Air Force employees. Nearly half of the participants were men and women who routinely work with jet fuel and had conducted tankentry tasks at least one hour, twice per week, at the same AF base for the past nine months. The remaining participants were men and women stationed on the same base but not routinely in contact with jet fuel. Personnel could not participate in the study if they had used alcohol 12 hours prior to the start of the study; had injuries requiring medical attention within the past 6 months; had a history of stroke, diabetes, or seizures; were pregnant; or were taking medications including diet pills, antidepressants, or hypertension drugs. The jet fuel research team consisted of approximately 30 researchers from six academic institutions, two government agencies, the USAF, and the United States Navy. Data from all seven heat stress evaluations will be used to determine any associations between heat stress and strain and fuel uptake and metabolism, and will be analyzed as possible confounders in various aspects of the risk assessment.
During the week of April 10-14, 2000, two NIOSH officers and other JP-8 study collaborators visited the aircraft fuel tank maintenance shop at D-M AFB. The work environment was assessed with wet bulb globe temperature (WBGT) monitors and by calculating the estimated metabolic heat load of each work task. The heat strain evaluation included personal monitoring of core body temperature (CBT), ear temperature, skin temperature, heart rate, activity levels, and pre- and post-activity body weights.

\section{BACKGROUND}

D-M AFB is an Air Combat Command installation located in Tucson, Arizona, and is home to the $355^{\text {th }}$ Wing unit which provides medical, logistical, and operational support to all other D-M units. The $355^{\text {th }}$ Wing is comprised of an operations group, a logistics group, a medical group, and a support group. D-M FSM employees are part of the logistics group under the 'Aircraft Fuel Cell Maintenance' activity. Approximately 40 employees rotate among two or three shifts depending upon the amount of work to be completed. FSM activities mostly take place inside metal non-air-conditioned hangars large enough for one to three planes, but can also occur outside on the flight line. One or two FSM crews work on a plane at one time, and their duties include removing any remaining jet fuel from the fuel cell, opening the entrance to the cell (usually a small port underneath the wing or on the fuselage), de-puddling the cell (removing the last of the fuel from the floor of the cell), and conducting maintenance activities. Breaks and lunch are taken in an air-conditioned room adjoining the hangar or outdoors.

Each crew consists of an entrant, attendant, runner, and shop supervisor. The entrant is responsible for going into the fuel cell, finishing the de-puddling, locating the area to be repaired or maintained, and removing large foam "sponges" to gain access to that area. (The foam sponges fill each fuel cell in specific order and are used for spark arrest in the event the plane's fuel tanks are damaged by gunfire.) The attendant is an assistant and backup for the entrant and usually stands just outside the porthole catching the foam removed by the entrant. The runner takes 
the foam from the attendant and arranges it in order on the floor of the hangar on absorbent material. The runner is also responsible for supplying parts, tools, and other necessities to the attendant, who then passes them on to the entrant. Crew members were previously cross trained and were observed to frequently rotate their activities during the study period. The shop supervisor, usually the highest in rank, oversees the operation and can act in any of the other three job categories if necessary. The crew members dress in thick $100 \%$ cotton coveralls and may wear pants and/or a T-shirt underneath. Some entrants and attendants also wear gloves and impermeable aprons over their coveralls, but most wore neither, and all of them entered the tank wearing only cotton socks on their feet. The entrants and some of the attendants wore supplied-air respirators. The respirator and confined space programs were evaluated by other members of the jet fuel study team.

Others exposed to JP-8 work in the fuels and fuelstransportation shops, commonly called petroleum, oils, and lubricants shops, or POLs, and as aircraft maintenance (avionics) specialists. POL responsibilities include refueling aircraft and filling and maintaining bulk fuel storage tanks, while maintenance specialists work with the planes' guidance and electrical systems. Work is mostly outdoors, but much time is spent in air-conditioned trucks driving from site to site. The uniform is the same thick $100 \%$ cotton coveralls, and T-shirts and pants are usually worn underneath.

The Tucson area's average high temperature is $82^{\circ} \mathrm{F}$, with an average low of $54^{\circ} \mathrm{F}$. The sun shines more than 85 percent of the time, and because of the city's elevation (2,581 feet), temperatures are generally mild. The average number of days hotter than $90^{\circ} \mathrm{F}$ is 138 , and the average number of days colder than $32^{\circ} \mathrm{F}$ is 19 . Average rainfall is 11 inches, and although Tucson rarely experiences snow, it does have winter, and temperatures can drop into the $30 \mathrm{~s}$ on winter mornings.

\section{METHODS}

WBGT measurements were collected using two RSS-214 WiBGeT ${ }^{\circledR}$ instruments (Imaging \& Sensing Technology, Horseheads, New York). These monitors are capable of measuring temperatures of $32^{\circ} \mathrm{F}-150^{\circ} \mathrm{F}$ and are accurate to within $\pm 0.5^{\circ} \mathrm{F}$. The WBGT index accounts for air velocity, temperature, humidity, and radiant heat and is a useful index of the environmental contribution to heat stress. It is a function of dry bulb temperature (a standard measure of air temperature taken with a thermometer), natural wet bulb temperature (simulates the effects of evaporative cooling), and black globe temperature (estimates radiant [infrared] heat load). One WBGT monitor was placed outdoors while the other was placed in the hangar on a work table near the work area. The monitors collected temperature data only during the hours worked by the study participants and therefore may not include the true high and low temperatures of each day. Also, because no data are available for conditions inside the fuel cell, environmental temperatures to which the entrant was exposed may be underestimated. Because the crew members dress in $100 \%$ cotton coveralls and may wear pants and/or T-shirt underneath, a clothing adjustment factor of $2^{\circ} \mathrm{F}$ was used to adjust the measured WBGTs during the data analysis. ${ }^{1}$

Metabolic rates for five different activities, including entrant, attendant, runner, POL/avionics specialist, and 'other', were estimated. The 'other' category includes scheduled and unscheduled breaks and all other non-working activities, such as time spent waiting for planes or parts to arrive, that are part of the work shift. Metabolic rates were estimated using the NIOSH table, "Estimated metabolic heat production rates by task analysis" (Appendix A). This method allows for specificity in rate estimation because it breaks the job down into categories that account for body position and movement, type of work, and basal metabolism.

Individual metabolic rates were estimated for the participants whose weights were available. The same NIOSH estimation method as for the activities 
was used (Appendix A). The NIOSH values are based upon a standard weight of 154 pounds (lbs), so a weight correction factor must be applied when workers weigh other than $154 \mathrm{lbs}$. The resulting estimates are also weighted to reflect the time the participants spent conducting each activity. Also, participants worked an 8-hour shift, but spent about 2 hours before and 2 hours after their FSM activities completing other components of the jet fuel study. No heat exposure monitoring occurred during these times. Therefore, the resulting estimates are not "full-shift" time-weighted averages and may underestimate participants' heat stress and strain levels. Individual results will vary depending on age, sex, fitness level, current health status, and body weight, and partly because of observer variability, errors in estimating metabolic rates may vary by $\pm 10-15 \%{ }^{2}$

Heat strain was assessed using the CorTemp ${ }^{\mathrm{TM}}$ Wireless Core Body Temperature Monitoring System (HTI Technologies, Inc., Palmetto, Florida). The CorTemp Temperature Sensor, a 0.9 x 0.4 inch silicon-coated electronic device, is swallowed and provides continuous monitoring of CBT to within $\pm 0.2^{\circ} \mathrm{F}$. The sensor is passed through the gastrointestinal tract and exits the body at participants' normal transit time, an average of approximately 72 hours. The sensor, intended for one-time use only, runs on a non-rechargeable silver-oxide battery and utilizes a temperature sensitive crystal which vibrates in direct proportion to the temperature of the substance surrounding it. This vibration creates an electromagnetic flux (frequency $=262.144$ kilohertz) which continuously transmits through the surrounding substance. A recorder, the CT2000, receives this signal and translates it into digital temperature information, which is then displayed on the unit and stored to memory. The CT2000 Recorder monitors temperatures of $50^{\circ} \mathrm{F}-122^{\circ} \mathrm{F}$. The recorder operates on one standard 9-volt alkaline battery, weighs about 7 ounces, and attaches to the user's belt. The participants' CBTs were recorded at 1-minute intervals.

Heat strain was also assessed using a Mini-Mitter Mini-Logger ${ }^{\mathbb{B}}$ Series 2000 (Mini-Mitter Company, Inc., Bend, Oregon). Heart rate, gross motor activity, skin temperature, and ear temperature, all of which directly impact or are a function of the body's metabolic rate, were monitored at 1-minute intervals. ${ }^{\text {a }}$ The participants were asked to wear an aural (ear) temperature probe, a skin temperature probe, Polar ${ }^{\circledR}$ chest band heart rate monitor, and an activity sensor on the dominant wrist. The MiniLogger's ear and skin temperature readings are accurate to within $\pm 0.18^{\circ} \mathrm{F}$ and have a range of $86^{\circ} \mathrm{F}-108^{\circ} \mathrm{F}$. The Polar chest band heart rate monitor counts up to 250 beats per minute (bpm) and is accurate to within \pm 1 heart beat. The activity monitor, which works by counting the number of movements per collection interval, is accurate to within \pm 1 millisecond and counts up to 65,353 movements per interval. The recorder weighs about 4 ounces and is worn on the user's belt.

Pre- and post-shift body weights were measured on 12 of 25 participants as part of the performance and balance measurements aspect of the jet fuel study and were used to determine the participants' degree of dehydration. Participants were weighed without socks and shoes using a self-calibrating Health o meter $^{\circledR}$, Inc., electronic digital strain-gauge scale, Model 842 , accurate to within $0.25 \mathrm{lbs}$ with a capacity of $300 \mathrm{lbs}$.

\section{EVALUATION CRITERIA}

To assess the hazards posed by workplace exposures, NIOSH investigators use a variety of environmental evaluation criteria for the assessment of chemical and physical agents. These criteria are intended to suggest levels of exposure to which most workers may be exposed for a working lifetime without

a The ear and skin temperature and activity measurements are not included in this report. No evaluation criteria exist for any of these measurements, and ear and skin temperatures are influenced by environmental conditions thereby decreasing their accuracy in heat stress assessments. Rather, these measurements will be compared to the CBT, heart rate, and WBGT measurements, which do have established criteria. Air Force personnel and management representatives will be provided with any future analyses of these measurements. 
experiencing adverse health effects. However, due to wide variation in individual susceptibility, a small percentage of workers may experience illness even if exposures are maintained below these limits. The criteria also do not account for individual sensitivity, pre-existing medical conditions, medicines taken by the worker, or possible interactions with other workplace agents.

The primary sources of environmental evaluation criteria for the workplace are NIOSH Recommended Exposure Limits (RELs), ${ }^{3}$ the American Conference of Governmental Industrial Hygienists' (ACGIH) Threshold Limit Values (TLVs), and the U.S. Department of Labor, Occupational Safety and Health Administration (OSHA) Permissible Exposure Limits (PELs). ${ }^{5}$ Employers are encouraged to follow the OSHA limits, the NIOSH RELs, and the ACGIH TLVs, or whichever are the more protective criteria. OSHA requires an employer to furnish employees a place of employment that is free from recognized hazards that are causing or are likely to cause death or serious physical harm (Occupational Safety and Health Act of 1970, Public Law 91-596, sec. 5(a)(1)). Employers should also understand that not all hazardous exposures, including heat stress, have specific OSHA PELs or short-term exposure limits (STELs); however, even in the absence of a PEL or STEL, an employer is still required by OSHA to protect employees from these hazards.

\section{Heat Stress}

NIOSH defines heat stress exposure as the sum of the heat generated in the body (metabolic heat) plus the heat gained from the environment (environmental heat) minus the heat lost from the body to the environment, which is primarily through evaporation. Many bodily responses to heat stress are desirable and beneficial because they help regulate internal temperature and, in situations of appropriate repeated exposure, help the body adapt (acclimate) to the work environment. However, at some stage of heat stress, the body's compensatory measures cannot maintain internal body temperature at the level required for normal functioning. As a result, the risk of heat-induced illnesses, disorders, and accidents substantially increases. ${ }^{2}$ Increases in unsafe behavior are also seen as the level of physical work of the job increases. ${ }^{2}$

Many heat stress guidelines have been developed to protect people against heat-related illnesses. The objective of any heat stress index is to prevent a person's CBT from rising excessively. The World Health Organization concluded that "it is inadvisable for CBT to exceed $38^{\circ} \mathrm{C}\left(100.4^{\circ} \mathrm{F}\right)$ or for oral temperature to exceed $37.5^{\circ} \mathrm{C}\left(99.5^{\circ} \mathrm{C}\right)$ in prolonged daily exposure to heavy work and/or heat." ${ }^{\prime 6}$ According to NIOSH, a deep body temperature of $39^{\circ} \mathrm{C}\left(102.2^{\circ} \mathrm{F}\right)$ should be considered reason to terminate exposure even when deep body temperature is being monitored. ${ }^{2}$ This does not mean that a worker with a CBT exceeding those levels will necessarily experience adverse health effects; however, the number of unsafe acts increases as does the risk of developing heat stress illnesses. ${ }^{2}$

NIOSH recommends that total heat exposure be controlled so that unprotected healthy workers who are medically and physically fit for their required level of activity and are wearing, at most, longsleeved work shirts and trousers or equivalent, are not exposed to metabolic and environmental heat combinations exceeding the applicable NIOSH criteria, as follows: Almost all healthy employees, working in hot environments and exposed to combinations of environmental and metabolic heat less than the NIOSH Recommended Action Limits (RALs) for non-acclimatized workers (Appendix B, Figure 1) or the NIOSH Recommended Exposure Limits (RELs) for acclimatized workers (Appendix B, Figure 2), should be able to tolerate total heat stress without substantially increasing their risk of incurring acute adverse health effects. Also, no employee should be exposed to metabolic and environmental heat combinations exceeding the applicable Ceiling Limits (C) of Figures 1 or 2 without being provided with and properly using appropriate and adequate heat-protective clothing and equipment. ${ }^{2}$

ACGIH guidelines require the use of a decisionmaking process which provides step-by-step situation-dependent instructions that factor in clothing insulation values and physiological 
evaluation of heat strain (see Evaluation Scheme for Heat Stress, Appendix C). ACGIH WBGT screening criteria (Appendix D) factor in the ability of the body to cool itself (clothing insulation value, humidity, wind), and, like the NIOSH criteria, can be used to develop work/rest regimens for acclimatized and unacclimatized employees. The ACGIH WBGT-based heat exposure assessment was developed for a traditional work uniform of longsleeved shirt and pants, and represents conditions under which it is believed that nearly all adequately hydrated, unmedicated, healthy workers, may be repeatedly exposed without adverse health effects. Clothing insulation values and the appropriate WBGT adjustments, as well as descriptors of the other decision-making process components can be found in ACGIH's Threshold Limit Values (TLVs ${ }^{\circledR}$ ) for Chemical Substances and Physical Agents and Biological Exposure Indices. ${ }^{4}$ The ACGIH TLV for heat stress attempts to provide a framework for the control of heat-related illnesses only. Although accidents and injuries can increase with increasing levels of heat stress, it's important to note that the TLVs are not directed toward controlling these. ${ }^{7}$

NIOSH and ACGIH criteria can only be used when WBGT data for the immediate work area are available and must not be used when wearing encapsulating suits or garments that are impermeable or highly resistant to water vapor or air movement. Further assumptions regarding work demands include an 8-hour work day, 5-day work week, two 15-minute breaks, and a 30-minute lunch break, with rest area temperatures the same as, or less than, those in work areas, and "at least some air movement." It must be stressed that NIOSH and ACGIH guidelines do not establish a fine line between safe and dangerous levels but require professional judgement and a heat stress management program to ensure protection in each situation.

OSHA does not have a specific heat stress standard, however, acceptable exposure to heat stress is enforced by the Secretary of Labor under the General Duty Clause [section 5(a)(1)]. ${ }^{8}$ The OSHA technical manual, Section III, Chapter $4,{ }^{9}$ provides investigation guidelines that approximate those found in ACGIH's 1992-1993 Threshold Limit
Values for Chemical Substances and Physical Agents and Biological Exposure Indices.

\section{Heat Strain}

The body's response to heat stress is called heat strain. ${ }^{2}$ Operations involving high air temperatures, radiant heat sources, high humidity, direct physical contact with hot objects, and strenuous physical activities have a high potential for inducing heat strain in employees. Heat strain is highly individual and cannot be predicted based upon environmental heat stress measurements. Physiological monitoring for heat strain becomes necessary when impermeable clothing is worn, when heat stress screening criteria are exceeded, or when data from a detailed analysis (such as the International Standards Organization [ISO] required sweat rate $\left[\mathrm{SR}_{\text {req }}\right]$ ) shows excess heat stress. $^{7}$

One indicator of physiological strain, sustained peak heart rate, is considered by ACGIH to be the best sign of acute, high-level exposure to heat stress. Sustained peak heart rate, defined by ACGIH as 180 beats per minute (bpm) minus an individual's age, is a leading indicator that thermal regulatory control may not be adequate and that increases in CBTs have, or will soon, occur. Sustained peak heart rate represents an equivalent cardiovascular demand of about $75 \%$ of maximum aerobic capacity. During an 8-hour work shift, although sustained peak demands may not occur, there may still be excessive demand placed on the cardiovascular system. These 'chronic' demands can be measured by calculating the average heart rate over the shift. Decreases in physical job performance have been observed when the average heart rate exceeds $115 \mathrm{bpm}$ over the entire shift. This level is equivalent to working at roughly $35 \%$ of maximum aerobic capacity, a level sustainable for 8 hours. ${ }^{7}$

According to ACGIH, an individual's heat stress exposure should be discontinued when any of the following excessive heat strain indicators occur:

- Sustained (over several minutes) heart rate is in excess of $180 \mathrm{bpm}$ minus the individual's age in years, $(180 \mathrm{bpm}-$ age $)$ for those with normal cardiac performance; 
- Core body temperature is greater than $38.0^{\circ} \mathrm{C}$ $\left(100.4^{\circ} \mathrm{F}\right)$ for unselected, unacclimatized personnel and greater than $38.5^{\circ} \mathrm{C}\left(101.3^{\circ} \mathrm{F}\right)$ for medically fit, heat-acclimatized personnel;

- Recovery heart rate at 1 minute after a peak work effort exceeds $110 \mathrm{bpm}$; or

- There are symptoms of sudden and severe fatigue, nausea, dizziness, or lightheadedness.

An individual may be at greater risk of heat strain if:

- Profuse sweating is sustained over several hours; or

- Weight loss over a shift is greater than $1.5 \%$ of body weight; or

- 24-hour urinary sodium excretion is less than 55 millimoles.

\section{Health Effects of Exposure to Hot Environments}

Heat disorders and health effects of individuals exposed to hot working environments include (in increasing order of severity) skin disorders (heat rash, hives, etc.), heat syncope (fainting), heat cramps, heat exhaustion, and heat stroke. Heat syncope (fainting) results from blood flow being directed to the skin for cooling, resulting in decreased supply to the brain, and most often strikes workers who stand in place for extended periods in hot environments. Heat cramps, caused by sodium depletion due to sweating, typically occur in the muscles employed in strenuous work. Heat cramps and syncope often accompany heat exhaustion, or weakness, fatigue, confusion, nausea, and other symptoms that generally prevent a return to work for at least 24 hours. The dehydration, sodium loss, and elevated CBT (above $100.4^{\circ} \mathrm{F}$ ) of heat exhaustion are usually due to individuals performing strenuous work in hot conditions with inadequate water and electrolyte intake. Heat exhaustion may lead to heat stroke if the patient is not quickly cooled and rehydrated.
While heat exhaustion victims continue to sweat as their bodies struggle to stay cool, heat stroke victims cease to sweat as their bodies fail to maintain an appropriate core temperature. Heat stroke occurs when hard work, hot environment, and dehydration overload the body's capacity to cool itself. This thermal regulatory failure (heat stroke) is a lifethreatening emergency requiring immediate medical attention. Signs and symptoms include irritability, confusion, nausea, convulsions or unconsciousness, hot dry skin, and a CBT above $106^{\circ} \mathrm{F}$. Death can result from damage to the brain, heart, liver, or kidneys. ${ }^{10}$

Prolonged increases in CBT and chronic exposures to high levels of heat stress are associated with disorders such as temporary infertility (male and female), elevated heart rate, sleep disturbance, fatigue, and irritability. During the first trimester of pregnancy, a sustained $\mathrm{CBT}$ greater than $102.2^{\circ} \mathrm{F}$ may endanger the fetus. ${ }^{4}$ In addition, one or more occurrences of heat-induced illness in a person predisposes him/her to subsequent injuries and can result in temporary or permanent loss of that person's ability to tolerate heat stress. ${ }^{2,9}$

The level of heat stress at which excessive heat strain will result is highly individual and depends upon the heat tolerance capabilities of each individual. Age, weight, degree of physical fitness, degree of acclimatization, metabolism, use of alcohol or drugs, and a variety of medical conditions, such as hypertension and diabetes, all affect a person's sensitivity to heat. At greatest risk are unacclimatized workers, people performing physically strenuous work, those with previous heat illnesses, the elderly, people with cardiovascular or circulatory disorders (diabetes, atherosclerotic vascular disease), those taking medications that impair the body's cooling mechanisms, ${ }^{\mathrm{b}}$ people who

${ }^{\mathrm{b}} \beta$-adrenergic receptor blockers and calciumchannel blockers, used to treat hypertension, limit maximal cardiac output and alter normal vascular distribution of blood flow in response to heat exposure. Diuretics, such as caffeine, can limit cardiac output and affect heat tolerance and (continued...) 
use alcohol or are recovering from recent use, people in poor physical condition, and those recovering from illness. A core body temperature increase of only $1.8^{\circ} \mathrm{F}$ above normal encroaches on the brain's ability to function.?

\section{Acclimatization}

When workers are first exposed to a hot environment, they show signs of distress and discomfort, experience increased CBTs and heart rates, and may have headaches and/or nausea. On repeated exposure there is marked adaptation to the hot environment known as acclimatization. Acclimatization is the process that allows the body to begin sweating sooner and more efficiently, reduces electrolyte concentrations in the sweat, and allows the circulation to stabilize so that the worker can withstand greater amounts of heat stress while experiencing reduced heat strain symptoms.

Acclimatization begins with consecutive exposures to working conditions for 2 hours at a time, with a requisite rise in metabolic rate. This will cause the body to reach $33 \%$ of optimum acclimatization by the fourth day of exposure. Cardiovascular stability and surface and internal body temperatures will be lower by day 8 when the body has reached $44 \%$ of optimum acclimatization. A decrease in sweat and urine electrolyte concentrations are seen at $65 \%$ of optimum (day 10); $93 \%$ of optimum is reached by day 18 and $99 \%$ by day $21 .{ }^{7}$

The loss of acclimatization begins when the activity under those heat stress conditions is discontinued, and a noticeable loss occurs after four days. This loss is usually rapidly made up so that by Tuesday workers who were off on the weekend are as well acclimatized as they were on the preceding Friday. Chronic illness, the use or misuse of pharmacologic agents, a sleep deficit, a suboptimal nutritional state, or a disturbed water and electrolyte balance may reduce the worker's capacity to acclimatize. ${ }^{7}$

b(...continued)

sweating, and antihistamines, phenothiazines, and cyclic antidepressants impair sweating. ${ }^{2}$

\section{Dehydration and Fluid Replacement}

When working in hot environments it is often difficult to completely replace lost fluids as the day's work proceeds. High sweat rates with excessive loss of body fluids may result in dehydration and electrolyte imbalances. ${ }^{11}$ Some studies have shown that even small deficits have adverse effects on performance. ${ }^{12}$ Dehydration also negates the advantage granted by high levels of aerobic fitness and heat acclimatization. ${ }^{13}$

Several studies have shown that dehydration increases CBT during exercise in temperate and hot environments; a deficit of only $1 \%$ of body weight increases CBT during exercise. As the magnitude of the water deficit increases, there is an accompanying elevation in CBT when exercising in the heat. The magnitude of this elevation ranges from $0.2^{\circ} \mathrm{F}$ to $0.4^{\circ} \mathrm{F}\left(0.1^{\circ} \mathrm{C}-0.23^{\circ} \mathrm{C}\right)$ for every $1 \%$ body weight loss. ${ }^{14}$ A $2 \%$ loss of body weight is generally accepted as the threshold for thirst stimulation. ${ }^{15} \mathrm{~A}$ $3 \%$ decrease in body weight causes an increase in heart rate, depressed sweating sensitivity, and a substantial decrease in physical work capacity. ${ }^{16}$ Some investigators have reported that a $4 \%$ to $6 \%$ water deficit has been associated with anorexia, impatience, and headache, while a $6 \%$ to $10 \%$ deficit is associated with vertigo, shortness of breath, cyanosis, and spasticity. With a $12 \%$ water deficit, an individual will be unable to swallow and will need assistance with rehydration. Lethal dehydration levels are estimated to occur at $15 \%$ to $25 \%$ lost body weight. ${ }^{17}$

Palatability of any fluid replacement solution is important to ensure adequate rehydration. There is evidence that adding sweeteners to drinks leads to increased consumption. Glucose-electrolyte solutions have been shown to facilitate sodium and water absorption. Also, the glucose in these solutions provides energy for muscular activity in endurance events that require vigorous exercise. ${ }^{18}$ The temperature of the drink will also influence consumption of fluids. Ideally, fluids should be ingested at $50^{\circ} \mathrm{F}-60^{\circ} \mathrm{F}$ in small quantities 
(5-7 ounces) and at frequent intervals (every 15-20 minutes).

\section{Hyponatremia (Water Toxicity)}

Most individuals with acute exercise-induced heat illness are dehydrated with normal to mildly increased serum sodium and serum osmolality (hypernatremia). Hyponatremia develops when serum sodium levels drop below $135 \mathrm{mEq} / \mathrm{L}$ and is a life-threatening condition that has been recognized as a potential health consequence of endurance activities conducted in hot environments. Increased water intake prior to and during activities in hot environments is highly emphasized to prevent dehydration and heat illness. However, drinking too much water can lead to decreased serum sodium concentrations (water toxicity or hyponatremia), and has been recognized as an increasing problem among US military recruits. ${ }^{19}$

Hyponatremia may occur with hypo-, hyper-, or normal hydration status. ${ }^{20}$ Symptomatic hyponatremia can occur when blood sodium concentrations decrease to less than $130 \mathrm{mEq} / \mathrm{L}$ and is generally caused by hypervolemia (water overload) secondary to extensive over-drinking. Many people with hyponatremia have increased their total body water by about 1 gallon to achieve such low serum sodium values. ${ }^{21}$

Most cases of hyponatremia result from the inability of the kidneys to excrete an appropriately dilute urine. The most significant clinical signs of hyponatremia involve the central nervous system, and symptoms vary from subtle changes in one's ability to think, to decreases in energy levels, to severe alterations, such as coma or seizure. Symptoms generally parallel the rate of development and degree of hyponatremia. ${ }^{22}$

\section{RESULTS}

\section{Workload and Task Assessments (Heat Stress)}

Table 1 lists the WBGTs measured during the study. Because of mechanical problems with the monitors, outdoor data are missing for one day, and indoor data are missing for three days of the five-day study period. Indoor WBGTs ranged from approximately $60^{\circ} \mathrm{F}$ to $73^{\circ} \mathrm{F}$, and outdoor WBGTs ranged from about $53^{\circ} \mathrm{F}$ to $82^{\circ} \mathrm{F}$. Table 2 lists the estimated metabolic rates for the five job categories which range from $138 \mathrm{kilocalories} \mathrm{per} \mathrm{hour} \mathrm{(} \mathrm{kcal} / \mathrm{hr}$ ) for 'other' activities to $288 \mathrm{kcal} / \mathrm{hr}$ for entrant activities and are therefore considered light to moderate workloads (see Appendix A for calculations and Appendix D for a description of the workload categories). Estimated individual metabolic rates ranged from $166 \mathrm{kcal} / \mathrm{hr}$ to $314 \mathrm{kcal} / \mathrm{hr}$ (Tables 3-7). According to the criteria, all of the participants were acclimatized to the work environment. When compared to the NIOSH and ACGIH screening criteria, the results indicate that none of the maintenance crew members were exposed to excessive heat stress conditions during the study.

\section{Physiological Monitoring (Heat Strain)}

Twenty-five participants were monitored for heat strain including twenty-three assigned to FSM activities, one assigned to POLs, and one avionics guidance and control systems specialist. Tables 3-7 list the results by study day. Sampling times ranged participants spent about 2 hours before and after their FSM activities completing other parts of the study and were not monitored for heat strain during these times. Five participants (20\%), all conducting FSM activities, experienced varying degrees of heat strain. One participant exceeded both the HR criterion (at least $14 \%$ of the duration of the activity) and the CBT criterion ( $44 \%$ of the duration of the activity), and two participants exceeded the heart rate criterion for approximately $6 \%$ and $7 \%$ of the duration of their activities. One participant exceeded the CBT criterion $53 \%$ of the duration of the activity, but had also reported having cold and/or allergy symptoms from 139 minutes to 246 minutes because 
the day of the study. The JP-8 study physician determined that the symptoms were not severe enough to exclude study participation, however, the symptoms may have caused an increase in CBT not due to heat stress. The middle- to end-of-shift CBT results from a second participant, who exceeded the CBT criterion for up to $43 \%$ of the duration of the activity, may have been heat-related. However, for approximately 30 minutes at the start of the activity, the CBT criterion was exceeded, suggesting potential artificial CBT elevation. Several factors may have caused this elevation including the ingestion of hot food or drink prior to swallowing the sensor and/or during the beginning of the shift, exercise or other work prior to participation, or impending illness. ${ }^{23}$ Three of the five participants who developed heat strain worked on different days of the study, and all five spent most of their time attending, less time entering, and little to no time running. Most participants reported being hot while working but those who developed heat strain did not report any heat strain symptoms such as weakness, excessive fatigue, nausea, or confusion.

Body weight changes among the 12 weighed participants ranged from $-2.3 \%$ to $+0.6 \%$, with a median percent body weight change of $-0.3 \%$. Two participants (17\%), working on different days, had greater than $1.5 \%$ body weight loss over their shifts indicating they were at greater risk of developing a heat-related illness, but neither exceeded the CBT or HR criteria during their activities. An additional seven participants $(58 \%)$, including one with heat strain signs, developed mild dehydration (body weight loss of $1.5 \%$ or less over the length of the shift) during their activities.

\section{Heat Stress Management at Davis-Monthan AFB}

D-M AFB has a formal heat stress policy (Base Instruction 48-1, dated July 1, 2000) based on criteria and recommendations from ACGIH, the National Safety Council, and the Air Force Manual, Personal Protection and Attack Actions (AFMAN
32-4005). The instruction, which applies to all D-M and Aerospace Maintenance Regeneration Center military and civilian personnel, describes policies and responsibilities for the prevention and control of the adverse effects of high temperatures. The WBGT index is the basis for the instruction which outlines WBGT monitoring procedures and provides WBGT limits for physical conditioning tasks and work/rest regimens for other tasks. Provisions for initiating OSHA 200 Occupational Illness Reports for heat stress injuries are also included, and reports of heat stress illnesses are to be forwarded to the bioenvironmental engineering (BEE) office for investigation and followup. All personnel are to be briefed prior to each hot weather season on factors affecting a body's response to heat stress. These factors include nutritional status, weather conditions, hydration, acclimatization, physical conditioning, alcohol and caffeine consumption, age, weight, lack of sleep/rest, and pregnancy. Preventive measures are emphasized. Types, causes, symptoms, and treatment of heat stress medical conditions are also to be included in the briefing.

\section{Discussion}

The study results indicate that those conducting FSM and other activities were not exposed to heat stress conditions in excess of the screening criteria. Despite this, 9 of the 12 participants (75\%) weighed before and after their activities became at least mildly dehydrated, and 5 of the total 25 (20\%) participants developed heat strain during their activities, as measured by CBT and/or HR levels that exceeded ACGIH heat strain criteria.

There were several limitations to this study. Some of the heat strain monitors failed and some employees weren't able to keep the heart rate and/or skin temperature sensors in place during the entire monitoring period; these incidences are identified in Tables 3-7. Therefore, some study results may have been over- or underestimated. Several aspects of the collaborative (JP-8) study may also have influenced the physiological monitoring results of the heat stress evaluation. Although participants worked for 8 hours, they did not work a 'normal' shift because their FSM activities constituted $50 \%$ or less of their 
time during the study. The other $50 \%$ of the shift involved completing other components of the jet fuel study for about 2 hours before and 2 hours after FSM work, in an air-conditioned building, usually seated and with lower metabolic rates than those estimated for FSM activities. There was no heat stress and participants were not monitored during these times. Therefore, the results are not "full-shift" timeweighted averages and may underestimate the heat stress and strain levels participants would have experienced had they conducted FSM activities for a full 8 hours. Also, some FSM employees, such as those taking certain medications, and those who were ill, pregnant, or had a history of strokes or seizures, were excluded from participating in the JP-8 study. All of these conditions, however, increase the risk of developing heat strain and heat-related illnesses, and the incidence of heat strain during the study may have been greater if individuals with these conditions had been allowed to participate.

Finally, as temperatures in Tucson increase during spring and summer, WBGTs will likely exceed NIOSH and ACGIH screening criteria thereby raising the potential for heat strain and illness among personnel. Heat strain is highly individual and cannot be predicted based upon environmental heat stress measurements alone. Some of the first symptoms of heat strain are hampered judgement and inability to think critically, symptoms which usually go unnoticed by the affected person. Study participants who developed heat strain reported feeling hot and sweaty but did not report noticing any feelings of fatigue, nausea, weakness, or confusion, which may indicate an individual lack of severity or lack of awareness of their heat strain.

\section{General Observations of the Davis-Monthan Heat Stress Instruction (48-1, 1 July 2000)}

The D-M AFB heat stress instruction provides clothing adjustment factors for various types of work clothing, including several types of water- and vaporbarrier protective suits. Clothing adjustment factors are used to lower the WBGT screening criteria to account for the wearer's increased heat stress load. The cloth coveralls worn by those conducting FSM activities are listed in the $\mathrm{D}-\mathrm{M}$ heat stress instruction as having a clothing adjustment factor of $+2^{\circ} \mathrm{F}$, which is appropriate according to the ACGIH TLV. ${ }^{4}$ However, water vapor- and air-impermeable encapsulating ensembles not worn by study participants, but worn by other D-M personnel also have clothing adjustment factors listed in the D-M heat stress instruction. The WBGT is not the appropriate measurement of environmental heat stress, and therefore, using a clothing adjustment factor is not appropriate. The NIOSH criteria document states that the adjusted air temperature $\left(\mathrm{t}_{\mathrm{adb}}\right)$ should be measured and used instead of the WBGT $\left(\mathrm{t}_{\mathrm{adb}}\right.$ is ambient dry bulb temperature adjusted for significant solar and long wave radiant heat loads). When $\mathrm{t}_{\text {adb }}$ exceeds $68^{\circ} \mathrm{F}$, physiological monitoring in the form of, for example, oral temperature and/or pulse rate is required. ${ }^{2}$ The ACGIH TLV for heat stress states that physiological monitoring must be performed when encapsulating suits or garments that are impermeable or highly resistant to water vapor or air movement or multiple layers of clothing are worn. ${ }^{7}$

The D-M AFB heat stress policy specifies that WBGTs be measured and reported to the various work areas Monday through Friday, May through September, and that measurements be made three times a day, except June through August, when a fourth daily measurement is required. This measurement schedule may not be sufficient, however, because WBGT data for the immediate work area should be available when using NIOSH and ACGIH screening criteria., ${ }^{2,4}$ NIOSH further recommends that environmental heat measurements be made at least hourly at the work area during the hottest part of the shift, during the hottest months of the year, and whenever a heat wave occurs or is predicted. If two sequential measurements exceed the RAL or REL, then work conditions should be modified by the use of engineering controls, work practices or other measures until two sequential measures are at or below the RAL or REL, whichever are applicable. ${ }^{2}$

Acclimatization to the work environment and selflimitation of heat stress exposure are two important ways to prevent heat-related illness. The physical conditioning chart provided in the base's heat stress 
policy is divided into temperature ranges and has instructions for non-acclimatized and acclimatized personnel; however, the policy's work/rest regimen chart does not distinguish between acclimatized and non-acclimatized personnel, nor does the policy provide guidelines for acclimating base personnel. Allowing employees to become used to working in the heat significantly increases their ability to do so safely and also decreases their risk of heat-related illnesses and unsafe acts. Significant loss of heat acclimatization can occur after only 4 days when exposure is discontinued, and if there is no exposure for a week or so, full acclimatization can require up to three weeks of continued physical activity under heat stress conditions. ${ }^{7}$ A properly designed and applied heat-acclimatization program is especially important for incoming (PCS) personnel, those on swing shifts or permanently transferred from nights to days, and those deployed to regions hotter than those from which they came. Self-limitation of exposure to the heat is also vital. The base policy states that the work/rest regimen is based upon the assumption that employees can stop work to prevent overheating, and during the study we noticed that the participants did take unscheduled breaks when needed. Allowing personnel to take unscheduled breaks during work in hot weather is an extremely important part of heat strain and illness prevention efforts, and it should be emphasized at every hot weather briefing and continue to be encouraged by all crew leaders.

\section{CONCLUSIONS}

Environmental temperature measurements and work load assessments showed that during the study period, those conducting fuel cell maintenance and other activities were not exposed to heat stress in excess of the occupational screening criteria. However, many participants complained of feeling hot and sweating, and some developed heat strain signs, including dehydration. Incidences of heat stress and strain may have been greater if participants had conducted FSM activities for their full 8-hour shift and if medically excluded workers had participated. In addition, the potential for heat stress and strain increases as temperatures rise during the spring and summer, and personnel should continue to be included in the D-M AFB heat stress management program. Study participants were not aware of having developed heat strain, indicating a need for further education and training, and for a physiological self-monitoring program.

\section{RECOMMENDATIONS}

The following recommendations are provided to enhance the D-M AFB heat stress policy in order to prevent and reduce future incidences of heat stress and strain among personnel.

Add personal monitoring (heat strain) education to the D-M AFB heat stress instruction. Those conducting FSM and other activities may be required to wear impermeable clothing and/or may be exposed to temperatures or physically demanding work rates which exceed recommended levels. Therefore, all personnel should be instructed on monitoring themselves and others for heat strain signs and symptoms. Personal monitoring is used in addition to environmental and metabolic monitoring, and involves checking the heart rate, oral temperature, extent of body weight loss, and/or recovery heart rate (see Appendix E). Measurements should be taken at appropriate intervals covering a full 2-hour period during the hottest parts of the day, and again at the end of the workday to ensure a return to baseline. ${ }^{2}$ Use of any of these techniques should always include 
the determination of baseline values for deciding whether individuals are fit to continue work that day.

$\checkmark$ Institute pre-placement and periodic medical examinations specifically for persons applying for and working in hot and/or physically demanding environments. Because aerobic capacities $\left(\mathrm{VO}_{2} \max \right.$ values) in the working population vary greatly, persons being considered for jobs requiring high metabolic demands should be specifically tested. The examination should be performed by a health care provider with knowledge of the health effects associated with work in hot and physically strenuous environments. The examinations should be performed to assess the physical, mental, and medical qualifications of the individuals and to exclude those with low heat tolerance and/or physical fitness. The health care provider should also update the information periodically for people working in these environments.

$\checkmark$ Establish a heat-acclimatization program. One that is properly designed and applied will dramatically increase the safety of workers in hot and physically demanding jobs and will decrease the risk of heat-related illnesses and unsafe acts. Such a program involves having employees work in hot environments for progressively longer periods. NIOSH recommends that workers who have had previous experience in jobs where heat levels are high enough to produce heat stress (CBT and heart rate increase but do not exceed recommended levels) should work in the environment $50 \%$ of the shift on day one, $60 \%$ on day two, $80 \%$ on day three, and $100 \%$ on day four. New workers who will be similarly exposed should start with $20 \%$ on day one, with a $20 \%$ increase in exposure each additional day. Being able to work $100 \%$ of the shift does not mean that workers will be fully acclimated after 5 days, but that they can work their entire shift in the work environment in which they were acclimatized. The body's acclimatization will continue to improve each day in that environment for up to 3 weeks. Figure 1 illustrates the acclimatization schedule for both types of workers for a 10-hour shift.

$\checkmark$ Monitor environmental heat exposures using a WBGT at or as close as possible to the area where the worker is exposed. WBGTs in break areas and other areas the employee may be working that differ in temperature should also be measured and used to calculate hourly time-weighted average WBGTs.

$\boldsymbol{V}$ Make at least hourly WBGT measurements during the hottest part of each shift, during the hottest months of the year and when heat waves occur or are predicted to occur. If two sequential measurements exceed the applicable criteria (RAL or REL or ACGIH TLV), then work conditions should be modified until two more sequential WBGT measurements are within the exposure limits.

$\checkmark$ Whenever personnel are required to wear air- and vapor-impermeable protective clothing, monitor the dry bulb or adjusted dry bulb temperatures, not the WBGT, and conduct physiological monitoring (Appendix E).

$\checkmark$ Encourage personnel to take unscheduled breaks if they report feeling weak, nauseated, excessively fatigued, confused, and/or irritable. These heat strain symptoms and any other signs of overexposure to the heat should be reported to the BEE office for investigation.

$\checkmark$ Hampered judgement and the inability to think critically, although some of the first symptoms of heat strain, usually go unnoticed by the person inflicted. Ensuring that crew members are wellhydrated, nourished, prepared, and not sleepdeprived or working too hard are some of the best ways to avoid heat strain, unsafe behavior, and poor job performance.

Personnel should drink enough water to stay hydrated and ideally should not lose any body weight during their shift. Always provide cool $\left(50-60^{\circ} \mathrm{F}\right)$ water or any cool liquid (except alcohol and caffeinated beverages) and encourage them to drink small amounts frequently, e.g., one cup every 20 minutes. Although some commercial drinks contain salt, this is not necessary because most people add enough salt to their diets.

$\checkmark$ Create a 'buddy' system so that crew members can monitor each other for signs of heat illness. A buddy system will help to ensure that each has had enough water and food and is feeling ok to continue. 
If a coworker appears to be disoriented or confused, or suffers inexplicable irritability, malaise, or flu-like symptoms, the worker should be removed for rest in a cool location with rapidly circulating air and kept under skilled observation. Immediate emergency care may be necessary. If sweating stops and the skin becomes hot and dry, immediate emergency care with hospitalization is essential. ${ }^{4}$

\section{REFERENCES}

1. Bernard T (tbernard@hsc.usf.edu) [2002]. Clothing adjustment factor for fuel cell maintenance crew coveralls. Private e-mail message to Ann Krake (amk3@cdc.gov), April 15.

2. NIOSH [1986]. Criteria for a recommended standard: occupational exposure to hot environments, rev. Cincinnati, OH: U.S. Department of Health and Human Services, Public Health Service, Centers for Disease Control, National Institute for Occupational Safety and Health, DHHS (NIOSH) Publication No. 86-113.

3. NIOSH [1992]. Recommendations for occupational safety and health: compendium of policy documents and statements. Cincinnati, $\mathrm{OH}$ : U.S. Department of Health and Human Services, Public Health Service, Centers for Disease Control, National Institute for Occupational Safety and Health, DHHS (NIOSH) Publication No. 92100.

4. ACGIH [2002]. $2002 \mathrm{TLVs}^{\circledR}$ and BEIs ${ }^{\circledR}$ : threshold limit values for chemical substances and physical agents \& biological exposure indices. Cincinnati, $\mathrm{OH}$ : American Conference of Governmental Industrial Hygienists.

5. CFR [1997]. 29 CFR 1910.1000. Code of Federal Regulations. Washington, DC: U.S. Government Printing Office, Federal Register.

6. WHO [1969]. Health factors involved in working under conditions of heat stress. Geneva, Switzerland: World Health Organization. Technical Report Series No. 412.
7. ACGIH [2001]. Heat stress and strain: documentation of TLVs and BEIs, $7^{\text {th }}$ ed. Cincinnati, $\mathrm{OH}$ : American Conference of Governmental Industrial Hygienists.

8. OSHA [1992]. 88-348 Industrial Glass. Occupational Safety and Health Review Commission and Administrative Law Judge Decisions. World Wide Web [URL=http:// www.osha-slc.gov/REVIEW data/ D19920421.html. April 2001.

9. OSHA [1999]. Technical manual, Section III: chapter 4, heat stress. World Wide Web [URL=http://www.osha-slc.gov/dts/osta/otm/ otm_iii/otm_iii_4.html], November 2001.

10. Cohen $\mathrm{R}$ [1990]. Injuries due to physical hazards. In: LaDou J, ed. Occupational Medicine. East Norwalk, CT: Appleton \& Lange.

11. Bates G, Gazey C, Cena K [1996]. Factors affecting heat illness when working in conditions of thermal stress. J Hum Ergon 25(1):13-20.

12. Sawka MN, Neufer PD [1993]. Interaction of water bioavailability, thermoregulation, and exercise performance. In: Marriott BM, ed. Fluid replacement and heat stress. Washington DC: National Academy Press, pp. 85-95.

13. Ekblom B, Greenleaf JE, Hermansen L [1970]. Temperature regulation during exercise dehydration in man. Acta Physiol Scand 79:475-483.

14. Sawka MN, Knowlton RG, Critz JB [1979]. The thermal and circulatory responses to repeated bouts of prolonged running. Med Sci Sports 11:177-180.

15. Szlyk PC, Sils JV, Francesconi RP [1989]. Variability in intake and dehydration in young men during a simulated desert walk. Aviat Space Environ Med 60:422-427.

16. Candas V, Libert JP, Brandenberger G [1985]. Hydration during exercise: Effects on thermal and cardiovascular adjustments. Eur $\mathrm{J}$ 
Appl Physiol 55:113-122.

17. Adolf EF and Associates [1947]. Physiology of man in the desert. New York, Interscience.

18. Rolls BJ, Kim S, Fedoroff IC [1990]. Effects of drinks sweetened with sucrose or aspartame on hunger, thirst and food intake in men. Physiol Behav 48:19-26.

19. Gardner JW [2002]. Death by water intoxication. Military Medicine 167(5):432-434.

20. Roetzheim R [1991]. Overhydration. Physician Sports Med 19:32.

21. Montain SJ, Latzka WA, Sawka MN [1999]. Fluid replacement recommendations for training in hot weather. Mil Med 164(7):502-508.

22. Devita MV, Michelis MF [1993]. Perturbations in sodium balance, hyponatremia and hypernatremia. Clinics in Lab Med 13(1):135-148.

23. Dinarello CA [1996]. Thermoregulation and the pathogenesis of fever. Infect Dis Clin Am 10(2):433- 449 . 


\section{Table 1: WBGT Environmental Temperature Data ${ }^{\alpha}$ \\ Davis-Monthan AFB, HETA 2000-0066}

\begin{tabular}{|c|c|c|c|c|}
\hline Date & $\begin{array}{c}\text { WBGT Range } \\
\text { Inside hangar }\end{array}$ & $\begin{array}{c}\text { Sampling Times } \\
\text { (Time of Highest Temp.) }\end{array}$ & $\begin{array}{c}\text { WBGT Range } \\
\text { Outside hangar }\end{array}$ & $\begin{array}{c}\text { Sampling Times } \\
\text { (Time of Highest Temp.) }\end{array}$ \\
\hline $4 / 10 / 00$ & $\Delta$ & & $\Delta$ & \\
\hline $4 / 11 / 00$ & $59.4-73.2^{\circ} \mathrm{F}^{\dagger}$ & $08: 47-13: 57(08: 56)$ & $55.0-70.2^{\circ} \mathrm{F}$ & $09: 18-13: 23(13: 06)$ \\
\hline $4 / 12 / 00$ & $59.6-61.4^{\circ} \mathrm{F}$ & $08: 14-15: 22(15: 15)$ & $52.8-80.2^{\circ} \mathrm{F}$ & $07: 42-15: 08(14: 49)$ \\
\hline $4 / 13 / 00$ & $\Delta$ & $\Delta$ & $60.3-81.5^{\circ} \mathrm{F}$ & $08: 10-14: 19(13: 37)$ \\
\hline $4 / 14 / 00$ & $\Delta$ & $\Delta$ & $63.6-76.4^{\circ} \mathrm{F}$ & $08: 17-14: 16(11: 26)$ \\
\hline
\end{tabular}

For heat stress exposure analysis, $2^{\circ} \mathrm{F}$ was added to the WBGT temperatures recorded inside the hangar to account for the insulation value of the coveralls worn by participants. ${ }^{1}$

${ }^{\Delta}$ Data not available because of equipment failure.

${ }^{\dagger}$ Note that temperatures were highest early on and continued to drop during the sampling period.

Table 2: Estimated Metabolic Rates for Fuel Cell Maintenance Activities Davis-Monthan AFB, HETA 2000-0066

\begin{tabular}{|cc|}
\hline Activity & Estimated Metabolic Rate (kcal/hr) \\
\hline Entrant & 288 \\
\hline Attendant & 246 \\
\hline Runner & 240 \\
\hline POL/Avionics specialist & 210 \\
\hline Other & 138 \\
\hline
\end{tabular}


Table 3: Physiological Measurement Results for 4-10-00

Davis-Monthan AFB, HETA 2000-0066

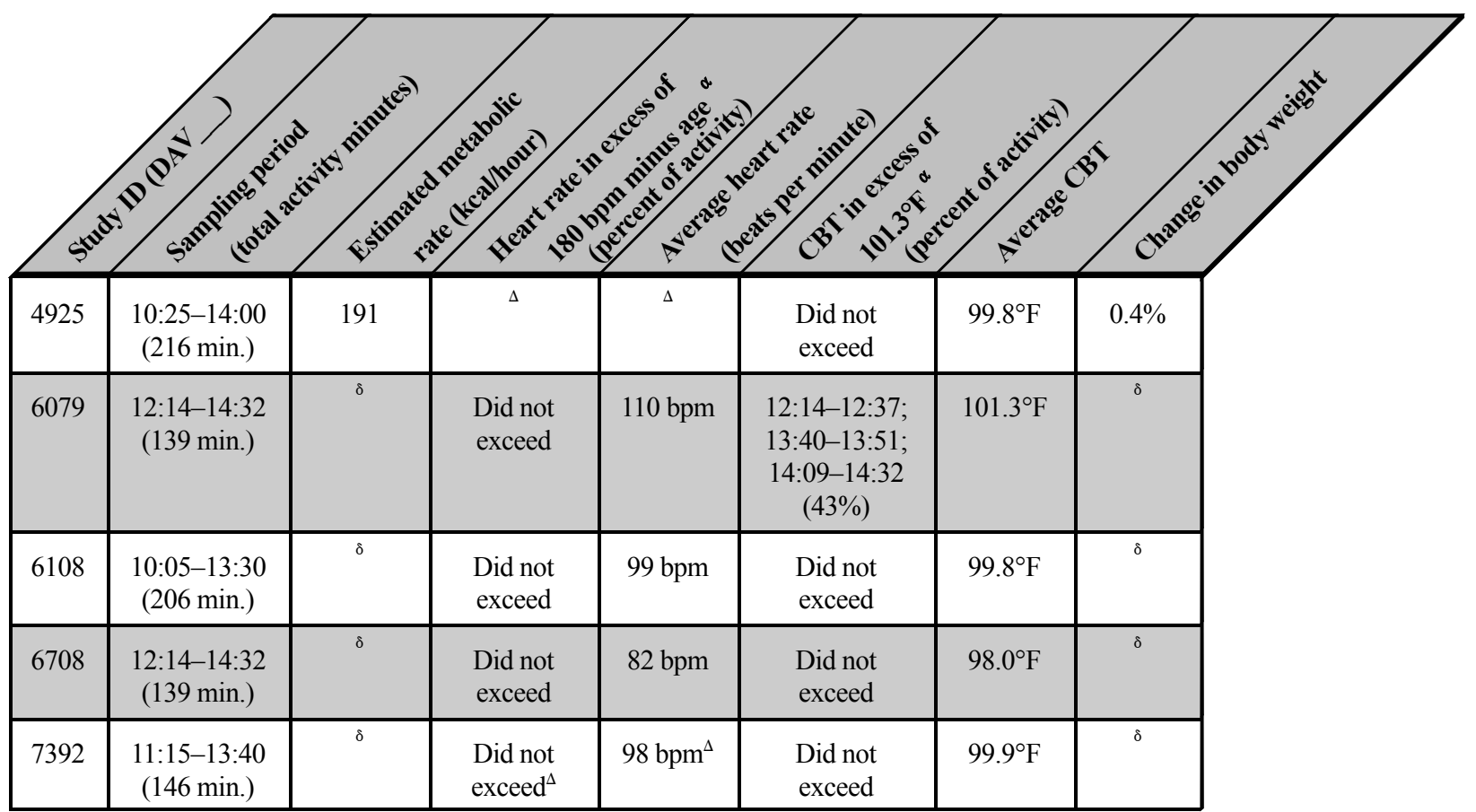

${ }^{\alpha}$ These are the main criteria used to determine heat strain. $\mathrm{CBT}=$ core body temperature.

${ }^{\Delta}$ Not all data available because of equipment failure or heart rate sensor slippage.

${ }^{\delta}$ No body weight was available for this participant, so these values could not be obtained.

Table 4: Physiological Measurement Results for 4-11-00 Davis-Monthan AFB, HETA 2000-0066

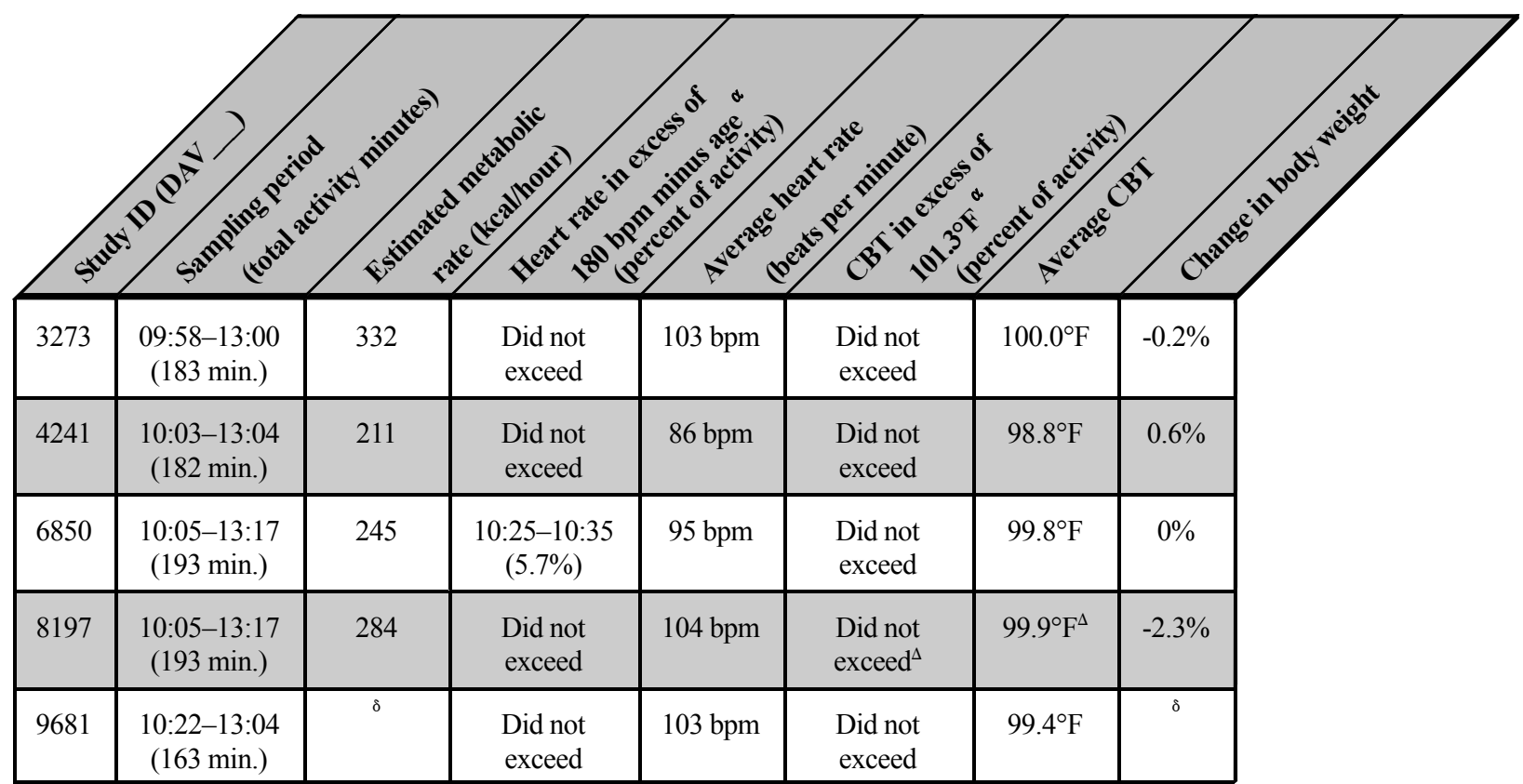

${ }^{\alpha}$ These are the main criteria used to determine heat strain. $\mathrm{CBT}=$ core body temperature.

${ }^{\Delta}$ Not all data available because of equipment failure or heart rate sensor slippage.

${ }^{\delta}$ No body weight was available for this participant, so these values could not be obtained. 
Table 5: Physiological Measurement Results for 4-12-00 Davis-Monthan AFB, HETA 2000-0066

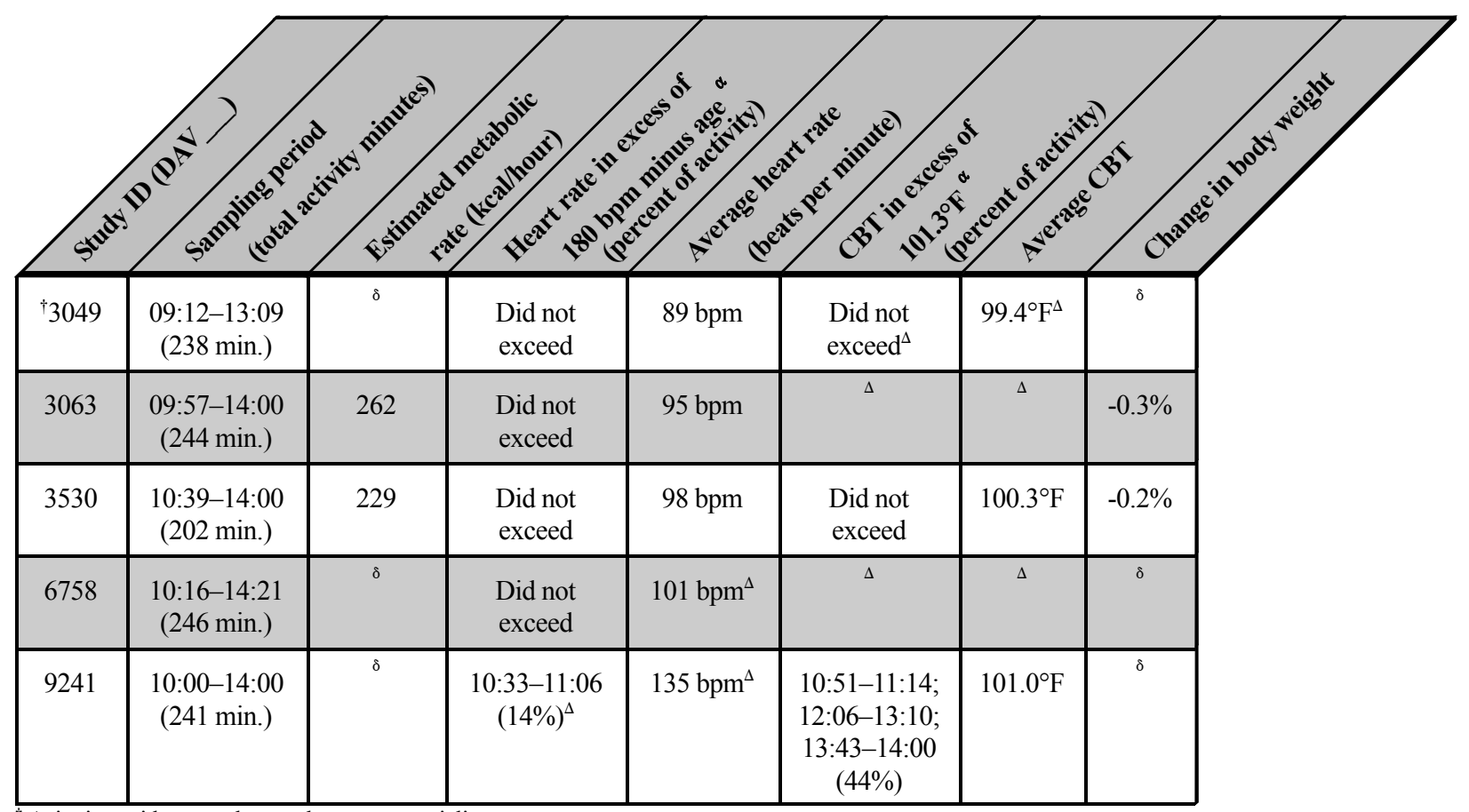

${ }^{\dagger}$ Avionics guidance and control systems specialist.

${ }^{\alpha}$ These are the main criteria used to determine heat strain. CBT $=$ core body temperature.

${ }^{\Delta}$ Not all data available because of equipment failure or heart rate sensor slippage.

${ }^{\delta}$ No body weight was available for this participant, so these values could not be obtained.

Table 6: Physiological Measurement Results for 4-13-00 Davis-Monthan AFB, HETA 2000-0066

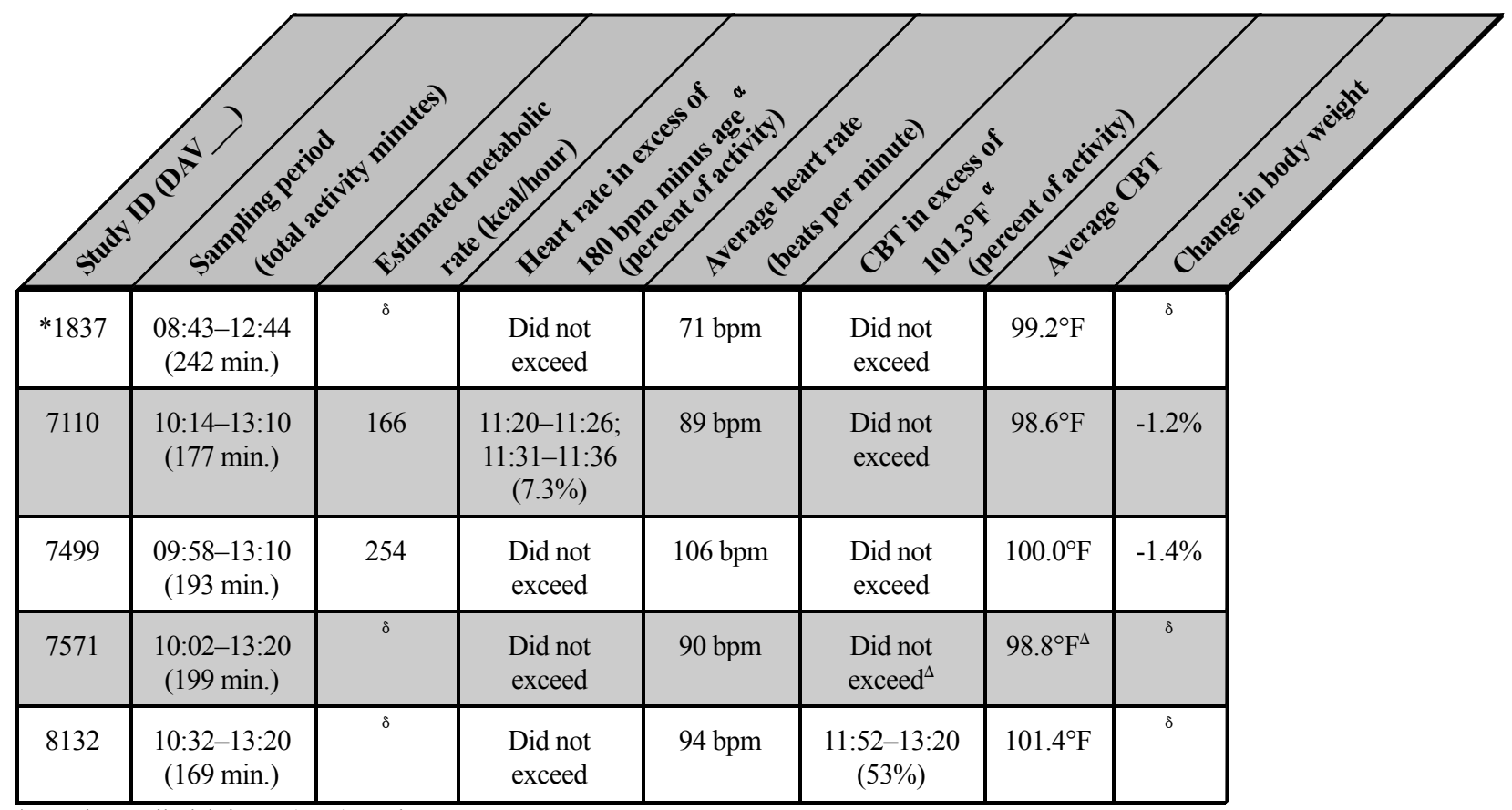

* Petroleum, oils, lubricants (POL) employee.

${ }^{\alpha}$ These are the main criteria used to determine heat strain. $\mathrm{CBT}=$ core body temperature.

${ }^{\Delta}$ Not all data available because of equipment failure or heart rate sensor slippage.

${ }^{\delta}$ No body weight was available for this participant, so these values could not be obtained. 
Table 7: Physiological Measurement Results for 4-14-00

Davis-Monthan AFB, HETA 2000-0066

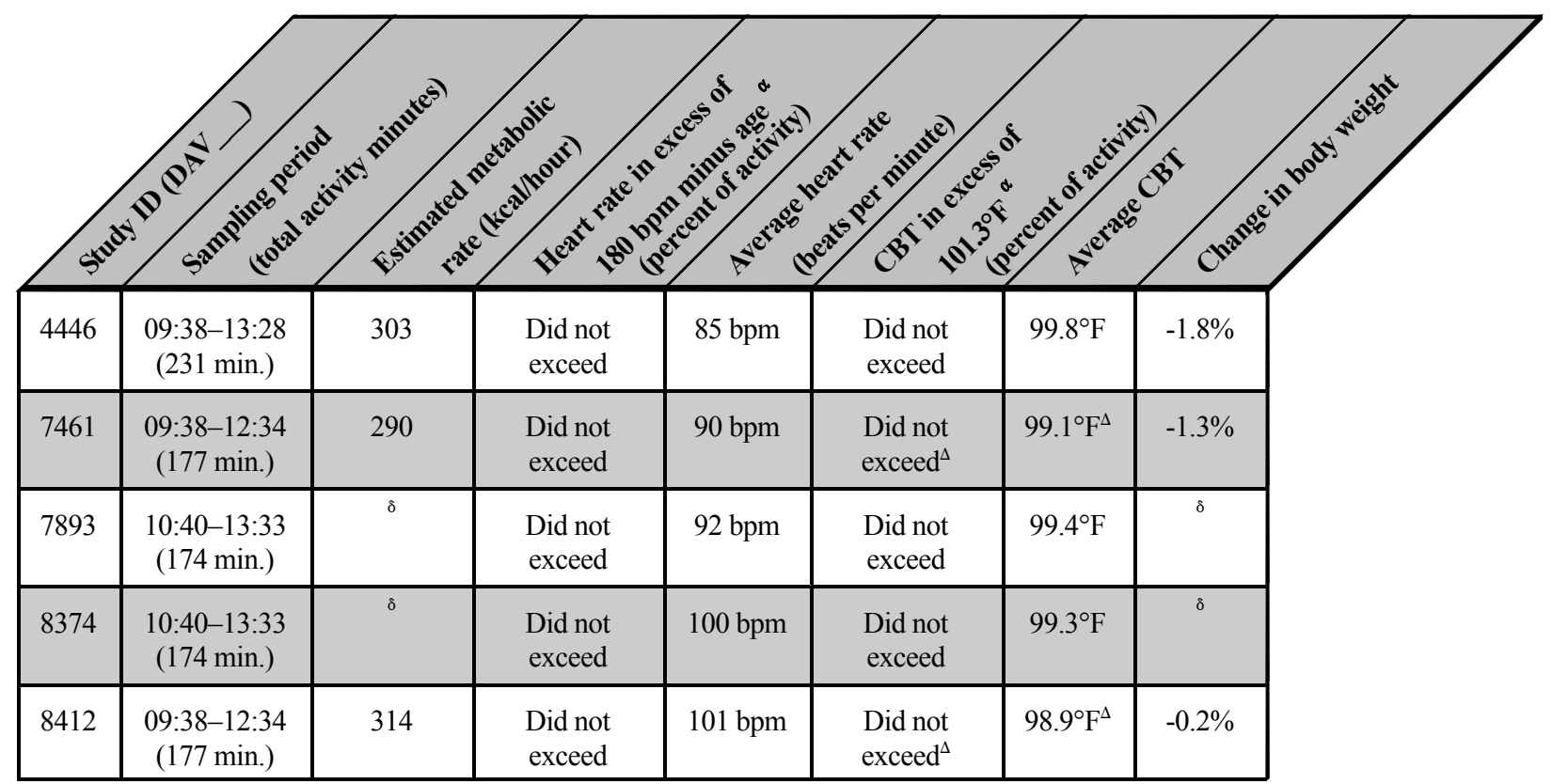

${ }^{\alpha}$ These are the main criteria used to determine heat strain. CBT $=$ core body temperature.

${ }^{\Delta}$ Not all data available because of equipment failure or heart rate sensor slippage.

${ }^{\delta}$ No body weight was available for this participant, so these values could not be obtained. 
Figure 1: Acclimatization schedules ${ }^{\mathrm{c}}$

Davis-Monthan AFB, HETA 2000-0066

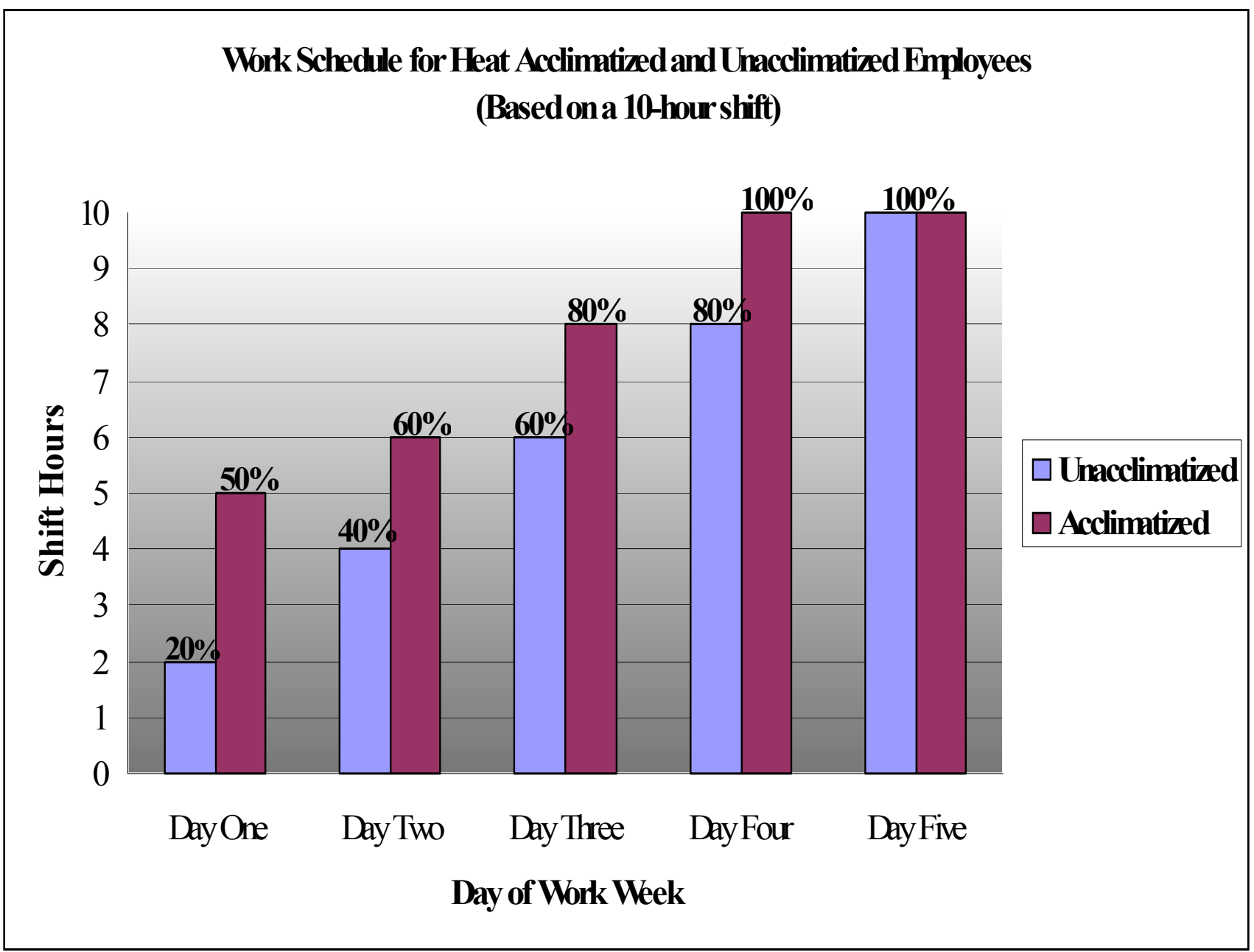

${ }^{\mathrm{c}}$ This illustration was created for this report from information in NIOSH [1986]. Criteria for a recommended standard: occupational exposure to hot environments, rev. Cincinnati, OH: U.S. Dept. of Health and Human Services, Public Health Service, Centers for Disease Control, National Institute for Occupational Safety and Health, DHHS (NIOSH) Publication No. 86-113. 
Appendix A: Assessment of Work

Estimated Metabolic Heat Production Rates by Task Analysis ${ }^{1}$

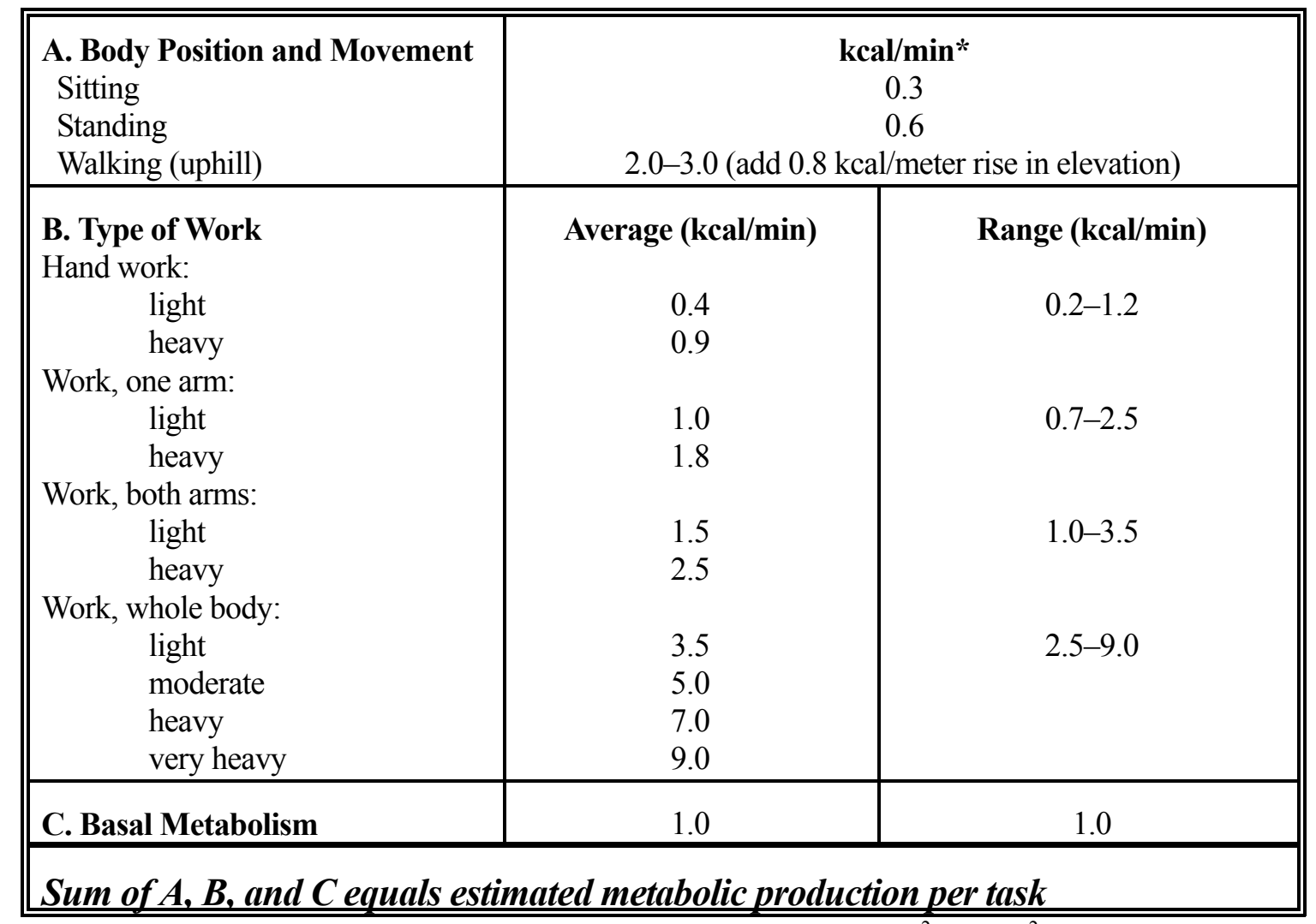

*For a standard male worker of $70 \mathrm{~kg}(154 \mathrm{lbs})$ body weight and $1.8 \mathrm{~m}^{2}\left(19.4 \mathrm{ft}^{2}\right)$ body surface.

\section{Sample calculation for the job of ENTRANT:}

$\underline{\text { Task }}$

A. Sitting

B. Light, whole body work

C. Basal metabolism

Metabolic Rate Total

D. Multiply by the weight correction factor $\underline{\mathrm{kcal} / \mathrm{min}}$

$0.3 \mathrm{kcal} / \mathrm{min}$

$3.5 \mathrm{kcal} / \mathrm{min}$

$1.0 \mathrm{kcal} / \mathrm{min}$

$4.8 \mathrm{kcal} / \mathrm{min} \times 60 \mathrm{~min} / \mathrm{hour}=288 \mathrm{kcal} /$ hour

$288 \mathrm{kcal} /$ hour x $1.05^{*}$

Total estimated metabolic rate $=302 \mathrm{kcal} / \mathrm{hour}^{\star}$

¥ The weight correction factor is used when an employee, plus any load they may have to carry, weigh other than 154 lbs. Calculate the factor by dividing the sum of the employee's current body weight (BW) and the load weight (LW) by $154 \mathrm{lbs}$ or $([\mathrm{BW}+\mathrm{LW}] \div 154 \mathrm{lbs}=$ weight correction factor $)$. A correction factor for a worker who weighs $162 \mathrm{lbs}$ and who is not carrying a load is calculated as: $(162 \mathrm{lbs}+0 \mathrm{lbs}) \div 154 \mathrm{lbs}=1.05$.

A Although not included in the following calculations, a correction factor specific to each employee would be applied under normal circumstances. 


\section{Appendix A: Assessment of Work (continued) Estimated Metabolic Heat Production Rates by Task Analysis ${ }^{1}$}

\section{Sample calculation for the job of ATTENDANT:}

$\underline{\text { Task }}$

A. Standing

B. 'Type of Work' - heavy work, both arms

C. Basal metabolism

Metabolic Rate Total

\section{$\underline{\mathrm{kcal} / \mathrm{min}}$}

$0.6 \mathrm{kcal} / \mathrm{min}$

$2.5 \mathrm{kcal} / \mathrm{min}$

$1.0 \mathrm{kcal} / \mathrm{min}$

$4.1 \mathrm{kcal} / \mathrm{min} \times 60 \mathrm{~min} /$ hour $=246 \mathrm{kcal} /$ hour

D. Multiply by the weight correction factor

3. Sample calculation for the job of RUNNER:

Task

A. Walking - can involve some climbing

B. 'Type of Work' - light work, both arms

C. Basal metabolism

Metabolic Rate Total

\section{$\mathrm{kcal} / \mathbf{m i n}$}

$1.5 \mathrm{kcal} / \mathrm{min}$

$1.5 \mathrm{kcal} / \mathrm{min}$

$1.0 \mathrm{kcal} / \mathrm{min}$

$4.0 \mathrm{kcal} / \mathrm{min} \times 60 \mathrm{~min} / \mathrm{hour}=240 \mathrm{kcal} /$ hour

D. Multiply by the weight correction factor

\section{Sample calculation for the job of POL:}

$\underline{\text { Task }}$

A. Sitting and standing

B. Light to medium work, both arms

C. Basal metabolism

Metabolic Rate Total

\section{$\underline{\mathrm{kcal} / \mathrm{min}}$}

$0.5 \mathrm{kcal} / \mathrm{min}$

$2.0 \mathrm{kcal} / \mathrm{min}$

$1.0 \mathrm{kcal} / \mathrm{min}$

$3.5 \mathrm{kcal} / \mathrm{min} \times 60 \mathrm{~min} /$ hour $=210 \mathrm{kcal} /$ hour

D. Multiply by the weight correction factor

5. Sample calculation for the job of 'OTHER':

$\underline{\text { Task }}$
A. Sitting
B. Light arm movement
C. Basal metabolism
Metabolic Rate Total

kcal/min

$0.3 \mathrm{kcal} / \mathrm{min}$

$1.0 \mathrm{kcal} / \mathrm{min}$

$1.0 \mathrm{kcal} / \mathrm{min}$

$2.3 \mathrm{kcal} / \mathrm{min} \times 60 \mathrm{~min} / \mathrm{hour}=138 \mathrm{kcal} / \mathrm{hour}$

D. Multiply by the weight correction factor 


\section{Appendix B: NIOSH Recommended Heat-Stress Alert and Heat-Stress Exposure Limits ${ }^{1, \text { a }}$}
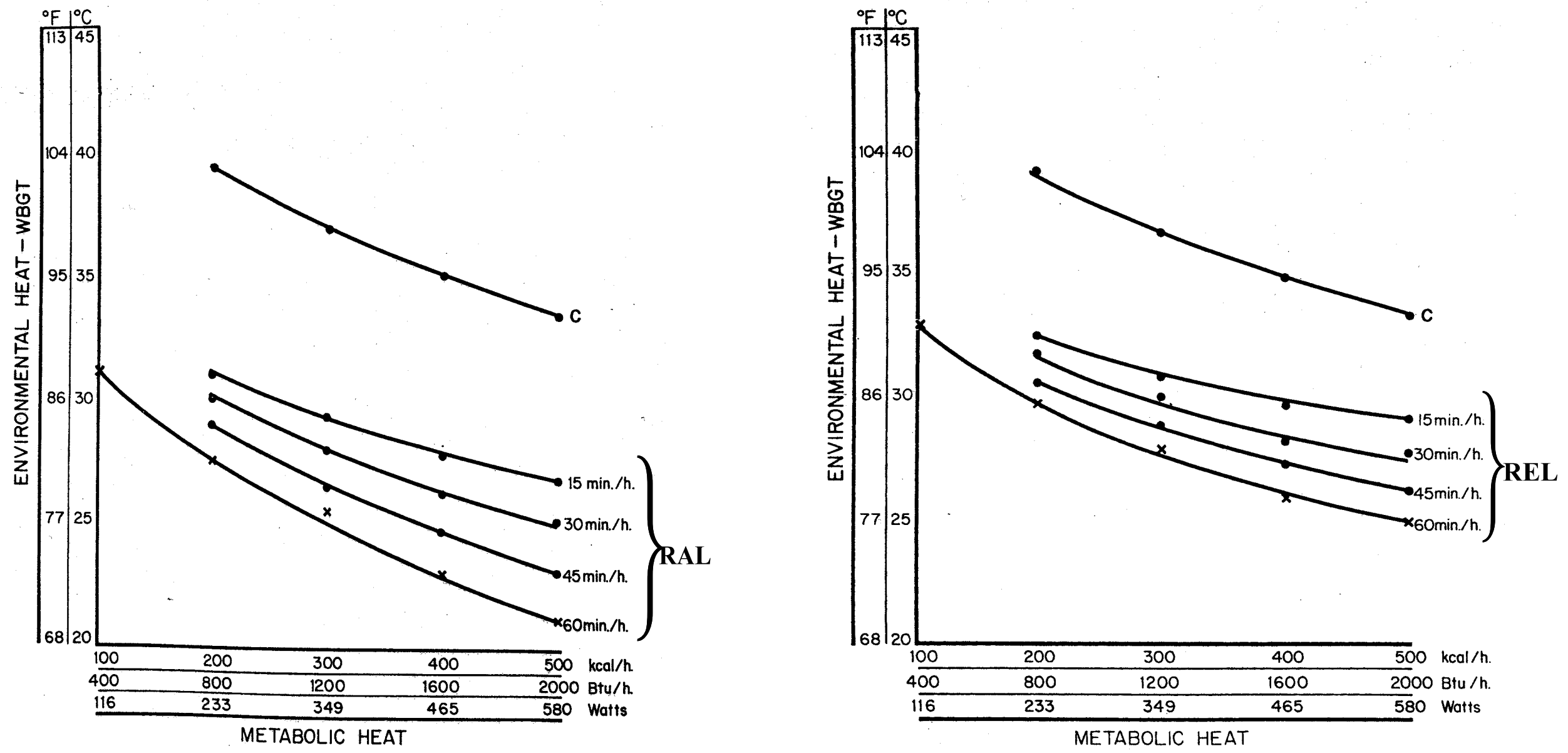

1. Recommended Heat-Stress Alert Limits (Unacclimatized Workers)

Figure 2. Recommended Heat-Stress Exposure Limits (Acclimatized Workers) a The figures' curves indicate recommended work/rest regimens for a combination of external heat (measured as wet-bulb globe temperatures) and internal (metabolic)
heat. The ' $\mathrm{C}$ ' curve is the Ceiling Limit, indicating that workers should not be exposed to such conditions without adequate heat-protective clothing and equipment. 


\section{Appendix C: ACGIH Evaluation Scheme for Heat Stress ${ }^{b}$}

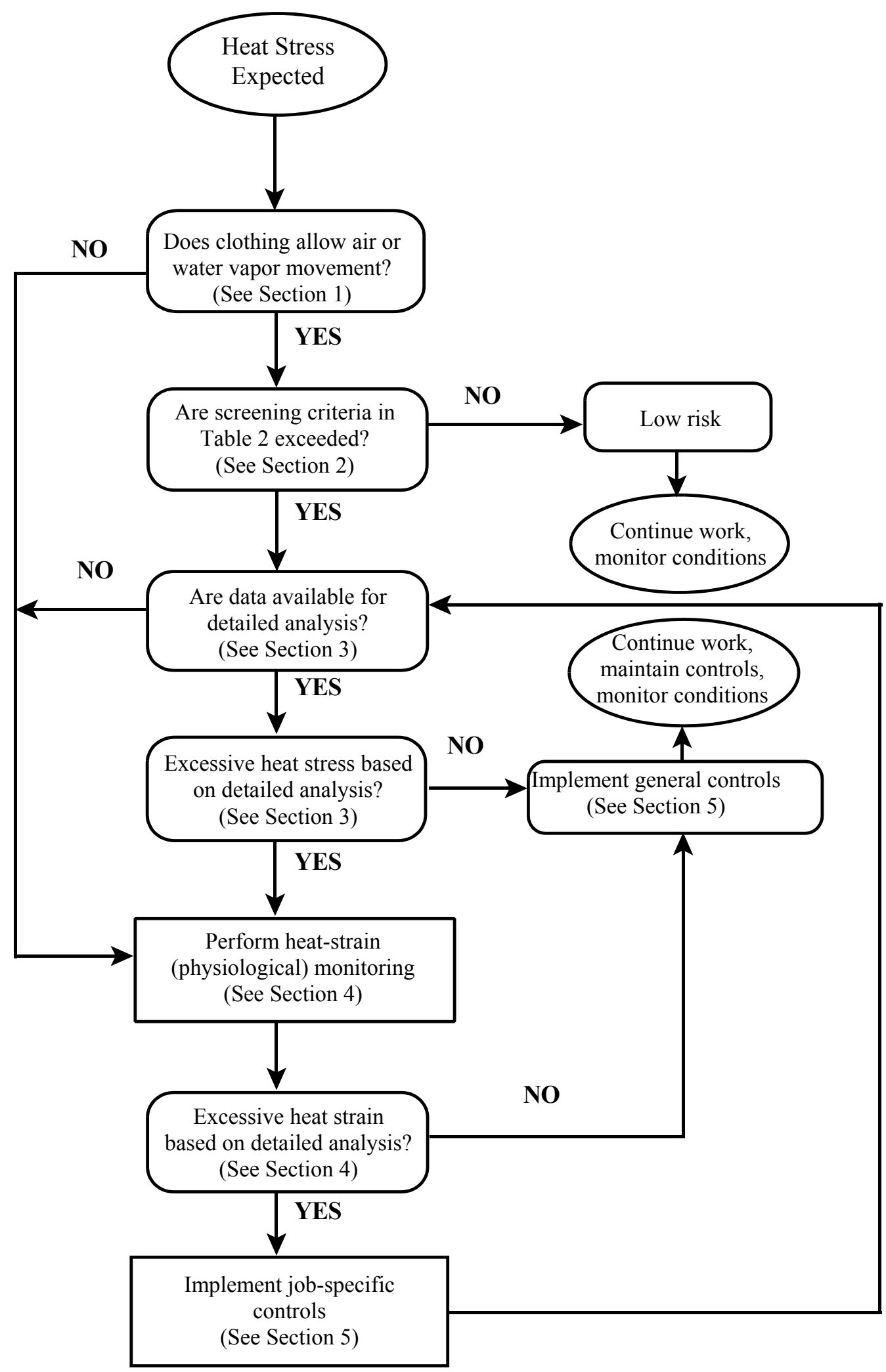

${ }^{\mathrm{b}}$ From American Conference of Governmental Industrial Hygienists $\left(\mathrm{ACGIH}^{\circledR}\right)$, Documentation of Threshold Limit Values and Biological Exposure Indices, $7^{\text {th }}$ Edition. Copyright 2001. Reprinted with permission. 
Appendix D: ACGIH Screening Criteria for Heat Stress Exposure ${ }^{c}$

\begin{tabular}{|c|c|c|c|c|c|c|c|c|}
\hline \multirow[b]{2}{*}{$\begin{array}{c}\text { Work } \\
\text { Demands }\end{array}$} & \multicolumn{4}{|c|}{ Acclimatized (WBGT values in $\left.{ }^{\circ} \mathbf{F}\right)$} & \multicolumn{4}{|c|}{ Unacclimatized (WBGT values in ${ }^{\circ}$ F) } \\
\hline & Light & Moderate & Heavy & $\begin{array}{l}\text { Very } \\
\text { Heavy }\end{array}$ & Light & Moderate & Heavy & $\begin{array}{c}\text { Very } \\
\text { Heavy }\end{array}$ \\
\hline $100 \%$ Work & 85.1 & 81.5 & 78.8 & & 81.5 & 77.0 & 72.5 & \\
\hline $\begin{array}{c}\text { 75\% Work; } \\
\text { 25\% Rest }\end{array}$ & 86.9 & 83.3 & 81.5 & & 84.2 & 79.7 & 76.1 & \\
\hline $\begin{array}{c}\text { 50\% Work; } \\
\text { 50\% Rest }\end{array}$ & 88.7 & 85.1 & 83.3 & 81.5 & 86.0 & 82.4 & 79.7 & 77.0 \\
\hline $\begin{array}{c}\text { 25\% Work; } \\
75 \% \text { Rest }\end{array}$ & 90.5 & 87.8 & 86.0 & 85.1 & 87.8 & 84.2 & 82.4 & 79.7 \\
\hline
\end{tabular}

Notes:

- See work demand categories table below.

- WBGT values represent thresholds near the upper limit of the metabolic rate category.

- If work and rest environments are different, hourly time-weighted averages (TWA) should be calculated and used. TWAs for work rates should also be used when the work demands vary within the hour.

- Values in the table assume 8-hour workdays in a 5-day workweek with conventional breaks as discussed in the Evaluation Criteria section of this report.

- Because of the physiological strain associated with Very Heavy work among less fit workers regardless of WBGT, criteria values are not provided for continuous work and for up to $25 \%$ rest in an hour. The screening criteria are not recommended, and a detailed analysis and/or physiological monitoring should be used.

The following work load categories, descriptions of work, and estimated energy expenditures help to estimate a conservative WBGT heat exposure limit for workers conducting these or similar jobs:

\begin{tabular}{|c|c|}
\hline Work Categories & Example Activities \\
\hline Resting & Sitting quietly; Sitting with moderate arm movements \\
\hline $\begin{array}{l}\text { Light } \\
(<200 \mathrm{kcal} / \mathrm{hr})\end{array}$ & $\begin{array}{l}\text { Sitting with moderate arm and leg movements; Standing with light work at } \\
\text { machine or bench while using mostly arms }\end{array}$ \\
\hline $\begin{array}{l}\text { Moderate } \\
(200-350 \mathrm{kcal} / \mathrm{hr})\end{array}$ & $\begin{array}{l}\text { Scrubbing in a standing position; Walking about with moderate lifting or } \\
\text { pushing; Walking on level at } 3.7 \text { mph while carrying a } 6.6 \text { pound load }\end{array}$ \\
\hline $\begin{array}{l}\text { Heavy } \\
(350-500 \mathrm{kcal} / \mathrm{hr})\end{array}$ & $\begin{array}{l}\text { Carpenter sawing by hand; Shoveling dry sand; Heavy assembly work on a } \\
\text { noncontinuous basis; Intermittent heavy lifting with pushing or pulling (e.g. } \\
\text { pick-and-shovel work) }\end{array}$ \\
\hline $\begin{array}{l}\text { Very Heavy } \\
(>500 \mathrm{kcal} / \mathrm{hr})\end{array}$ & Shoveling wet sand \\
\hline
\end{tabular}

c From American Conference of Governmental Industrial Hygienists $\left(\mathrm{ACGIH}^{\circledR}\right)$, Documentation of Threshold Limit Values and Biological Exposure Indices, $7^{\text {th }}$ Edition. Copyright 2001. Reprinted with permission. 


\title{
Appendix E: Use of Personal Monitoring Methods to Reduce Heat-Related Illnesses ${ }^{1}$
}

\author{
Periodic monitoring of the heart rate, oral temperature, extent of body weight loss, \\ and/or recovery heart rate should always include the determination of baseline \\ values for deciding whether individuals are fit to continue work that day.
}

$\checkmark$ Heart rate: Calculate your heart rate limit by subtracting your age from 180 . Your heart rate at peak work effort should not exceed this number for more than 3 or 4 minutes. If it does, stop work immediately, find some shade, drink, and rest until your heart rate returns to a more normal pace. Repeat as necessary.

$\checkmark$ Oral Temperature: Use a clinical thermometer right after stopping work but before drinking anything. Try to avoid open-mouth breathing prior to inserting the thermometer, as well. If the oral temperature taken under the tongue exceeds $99.7^{\circ} \mathrm{F}$, shorten the next work cycle by one-third and maintain the same rest period. An oral temperature of $100.4^{\circ} \mathrm{F}$ (deep body temperature of $102.2^{\circ} \mathrm{F}$ ) should be considered reason to terminate exposure even when temperature is being monitored.

$\checkmark$ Body Weight: Monitor hydration status on a regular basis. Thirst is a poor indicator of hydration because significant dehydration has already taken place when the thirst sensation occurs. Workers should be familiar with their weight when they are fully hydrated and should strive to maintain this weight. Weight loss should not exceed $1.5 \%$ of total body weight in a work day. If it does, fluid and food intake should increase. (Alcohol and caffeinated beverages should always be avoided when working under heat stress conditions.) Workers should attempt to re-hydrate themselves until they achieve their baseline weight. For this purpose, accurate scales should be made available at every work station. Body water loss can be measured by weighing the worker at the beginning and end of each work day and by using this equation:

(pre-activity weight - post-activity weight $) \div$ pre-activity weight $\times 100=\%$ body weight lost

$\checkmark$ Recovery Heart Rate: Following a normal work cycle, compare a pulse rate taken at 3 minutes of seated rest, $\mathbf{P}_{3}$, with the pulse rate taken at 1 minute of rest, $\mathbf{P}_{\mathbf{1}}$. Interpret the results using the following table:

\begin{tabular}{|lll|}
\multicolumn{1}{|l}{ Heart Rate Recovery Pattern } & $\mathbf{P}_{\mathbf{3}}$ & $\mathbf{P}_{\mathbf{1}}$ minus $\mathbf{P}_{\mathbf{3}}$ \\
\hline Excessive heat strain: & $\succeq 90 \mathrm{bpm} \quad$ and $\quad \leq 10 \mathrm{bpm}$ \\
\hline Moderate strain: & $\succeq 90 \mathrm{bpm}$ and $\quad \succeq 10 \mathrm{bpm}$ \\
\hline Sufficient recovery: & $\prec 90 \mathrm{bpm} \quad$ and $\quad \succ 10 \mathrm{bpm}$ \\
\hline
\end{tabular}




\section{REFERENCE}

1. NIOSH [1986]. Criteria for a recommended standard: occupational exposure to hot environments, rev. Cincinnati, OH: U.S. Department of Health and Human Services, Public Health Service, Centers for Disease Control, National Institute for Occupational Safety and Health, DHHS (NIOSH) Publication No. 86-113. 
DEPARTMENT OF HEALTH AND HUMAN SERVICES Centers for Disease Control and Prevention

National Institute for Occupational Safety and Health 4676 Columbia Parkway

Cincinnati, OH 45226-1998

OFFICIAL BUSINESS

Penalty for private use $\$ 300$

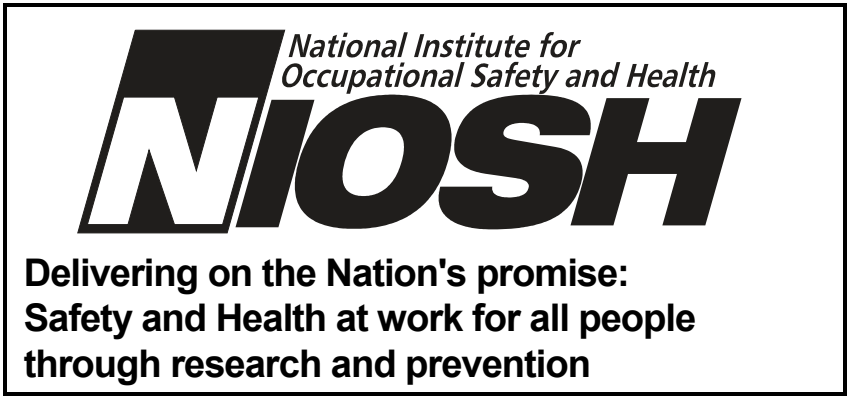

To receive NIOSH documents or information about occupational Safety and Health topics contact $\mathrm{NIOSH}$ at:

1-800-35-NIOSH (356-4674) Fax:

1-513-533-8573 E-mail: pubstaft@cdc.gov

or visit the NIOSH web site at:

www.cdc.gov/niosh/homepage.html

SAFER • HEALTHIER • PEOPLETM 